\title{
Review Article \\ Recycling of Waste Sludge: Preparation and Application of Sludge-Based Activated Carbon
}

\author{
Yongning Bian, ${ }^{1,2}$ Qian Yuan, ${ }^{1,2}$ Guocheng Zhu $\mathbb{D}^{1,2}$ Bozhi Ren $\mathbb{D}^{1},^{1}$ \\ Andrew Hursthouse $\mathbb{D}^{1,3}$ and Peng Zhang ${ }^{2}$ \\ ${ }^{1}$ Hunan Provincial Key Laboratory of Shale Gas Resource Utilization and Exploration, Xiangtan 411201, China \\ ${ }^{2}$ College of Civil Engineering, Hunan University of Science and Technology, Xiangtan 411201, China \\ ${ }^{3}$ School of Science and Sport, University of the West of Scotland, Paisley PA1 2BE, UK \\ Correspondence should be addressed to Guocheng Zhu; zhuguoc@hnust.edu.cn
}

Received 10 October 2017; Revised 13 February 2018; Accepted 22 February 2018; Published 19 June 2018

Academic Editor: Cornelia Vasile

Copyright ( 2018 Yongning Bian et al. This is an open access article distributed under the Creative Commons Attribution License, which permits unrestricted use, distribution, and reproduction in any medium, provided the original work is properly cited.

\begin{abstract}
With the rapidly increasing industrial and agricultural development, a large amount of sludge has been produced from much water treatment. Sludge treatment has become one of the most important environmental issues. Resource utilization of sludge is one of the important efficient methods for solving this issue. Sludge-based activated carbon (SBAC) materials have high adsorption performance and can effectively remove environmental pollutants including typical organic matter and heavy metals through physical and chemical processes. Therefore, developing efficient SBAC materials is important and valuable. At present, preparation, modification, and application of SBAC materials have gained widespread attention. This paper provides a review of the research on SBAC preparation and modification and its utilization in removing environmental pollutants. It included the following topics present in this review: conventional and new methods for preparation of SBAC were clearly present; the effective methods for improving SBAC performance via physical and chemical modification were reviewed; and the correlation of their physic-chemical properties of SBAC with pollutants' removal efficiencies as well as the removal mechanisms was revealed. SBAC has a better adsorption performance than commercial activated carbon in some aspects. Furthermore, it is a cost-effective technique and has a wide range of raw materials. However, there are still some drawbacks to its research; thus, some suggestions for further research were given in this review.
\end{abstract}

\section{Introduction}

With the rapid development of water treatment industry, the amount of activated sludge produced by treating sewage increases [1]. Because activated sludge is characterized by high water content, loose structure, a large amount of organic matter, and poisonous and harmful substances (such as microorganism, heavy metal, and poisonous organism) [2], it has become an important environmental issue and needs to be treated through an effective pathway. At present, sludge utilization has become one of the important methods for sludge disposal [3-5]. For example, sludge-based activated carbon (SBAC) material which is prepared with treated activated sludge can be used to adsorb and treat pollutants $[6,7]$. The material is a black amorphous carbon material made by activated sludge that came from water treatment, which is made by blending, carbonization, activation, and so on. It has the characteristic of a dense pore, complex pore structure, and large specific surface area; so, it has higher absorbability [8]. In the 1970s, using sewage sludge as raw material to prepare SBAC has been reported [9]. Its preparation and application have become one of the pathways to dispose the waste sludge.

SBAC is an environment-friendly adsorbent [10], which has good adsorption performance, wide range of source of raw material, stable chemical properties, and repeated utilization and recovery. In addition, it has good thermal stability and also has been reported to be safe for use at present [11]. Therefore, its focus has been moved to how to enhance the performance of SBAC. The selections of carbonization activation process and carbonization material are therefore important for the preparation. For example, prepared by 
phosphoric acid activation and microwave pyrolysis, the SBAC has excellent performance in adsorption of organic matters. As a result, the maximum methylene blue adsorption value by the SBAC is higher than that by the activated carbon for purified water [12]. Good SBAC material is important for economic and social development; preparation and application of SBAC have received extensive attention in the field of environmental protection. Also, more and more researches are reported and push the development of sludge utilization exploration. At present, the direction of the preparation method of SBAC material which has previously obtained the characteristics of a specific physicochemical property is not clear. Therefore, this paper adopts different classification models to summarize the preparation and application process of SBAC and to clarify the method of constructing and applying SBAC with specific physicochemical structure. The short review was aimed to review the development of SBAC in its modification and environmental application using different classification models.

\section{The Preparation of SBAC}

SBAC can be prepared by direct pyrolysis method [13, 14], physical activation process $[15,16]$, chemical activation process [17, 18], physical-chemical activation process [19], microwave activation [20], and so on. These methods can be used to produce porous carbon-adsorbing materials. The physical activation often uses traditional Muffle furnace heating method, while microwave activation has received much attention because of its high efficiency and easy control. Menéndez et al. [21] have demonstrated that the microwave preparation of activated carbon is highly feasible. The carbon content of SBAC would be low; adding carbon source material (e.g., corn kernel [22, 23], wood chip [24], peanut shell [25], and hazelnut shell [26]) is the possible increase of carbon source supply, which potentially enhances its efficient use in large scale. For instance, adding 20\% of the peanut shells to the municipal sludge as carbon sources, the SBAC developed by Jingjing [27] exhibited abundant pore structures and strong adsorption performance.

Figure 1 shows the modification and preparation pattern of SBAC, including direct pyrolysis, physical activation process, chemical activation, and physical-chemical activation. Direct pyrolysis is carried out under inert gas to obtain SBAC by directly drying and pulverizing activated sludge [28]. It consists of three stages: the dehydration stage, the second stage in which the large amount of volatile components are dissolved out in the pyrolytic zone, and the third stage where the residual material continues to be slowly pyrolyzed [29]. Physical activation (gas activation method) is able to directly pyrolyze and dry the grinding-activated sludge under inert gas protection and then pyrolyze it again thus obtaining SBAC under the other protective gas (such as $\mathrm{CO}_{2}$ [30], water vapor [31], and flue gas [32]). Chemical activation puts raw sludge materials and chemical reagents together at a ratio [33] or dip-dried sludge in chemical reagent solution according to a certain solid-liquid ratio [34] and then pyrolyzes the hybrid product for SBAC [35], as shown in Figure 2. Physical-chemical activation mixes the sludge with

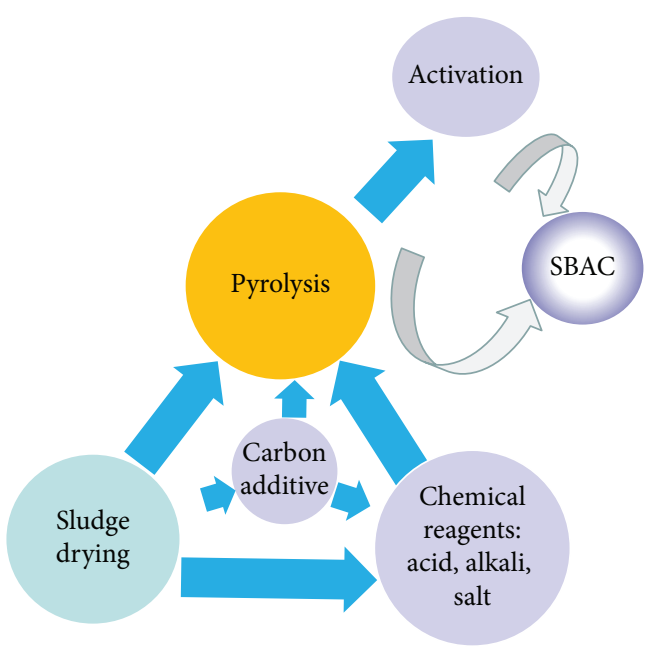

FIgURe 1: The mode for preparation of SBAC.

the chemical reagent in a proportion ratio; thereafter, they are pyrolyzed to obtain SBAC under the protection of inert gas [19]. Microwave activation pyrolyzes and carbonizes sludge into SBAC through microwave heating [36-38]. Compared with the traditional activation processes, the microwave activation has the advantages of high efficiency, low energy consumption, low cost, and small pollution [39].

\section{Modification of SBAC}

The factors that influence SBAC-specific surface area, adsorption yield of activated carbon, surface functional groups of activated carbon, and other characters include activation reagent class, activation temperature, activator concentration, pyrolysis time, impregnation ratio, and excess substance ratio [41]. The pretreatment of sludge also affects the performance of SBAC, such as the sludge treated with Fenton pretreatment, which can effectively improve SBAC characters [42] The electro-Fenton (EF) process is a new electrochemical process that produces free radicals and iron ions. When using iron as an anode, $\mathrm{H}_{2} \mathrm{O}_{2}$ is produced by dissolved oxygen electrolysis and $\mathrm{Fe}^{2+}$ is produced by electrolytic corrosion of anode. The combination of $\mathrm{H}_{2} \mathrm{O}_{2}$ and $\mathrm{Fe}^{2+}$ can produce strong oxidative free radicals, having a high oxidation potential up to $2.8 \mathrm{eV}$. In the EF process, the sludge flocculation products are to be broken and destabilized and the decomposed flocculation products are complexed with oxidized $\mathrm{Fe}^{3+}$ to enhance metal dispersion and modification [43]. Gu et al. [44] showed a simple method for loading the magnetic carbon to Fe nanoparticle (EF-SBAC) using EF pretreatment sludge, as shown in Figure 3. A new-type magnetic sludge-derived carbon was synthesized by continuous EF activation and carbonization, which had a good physicchemical property, including high $\mathrm{Fe}$ insertion rate $(74 \%)$, small size $(4.77 \mathrm{~nm})$ of nanoparticles, and good dispersion. The EF-SBAC revealed good catalytic activity, stability, and availability. For example, EF-SBAC could remove 96.1\% methyl orange within $60 \mathrm{~min}$, while its iron leaching rate was only $1.4 \%$. 


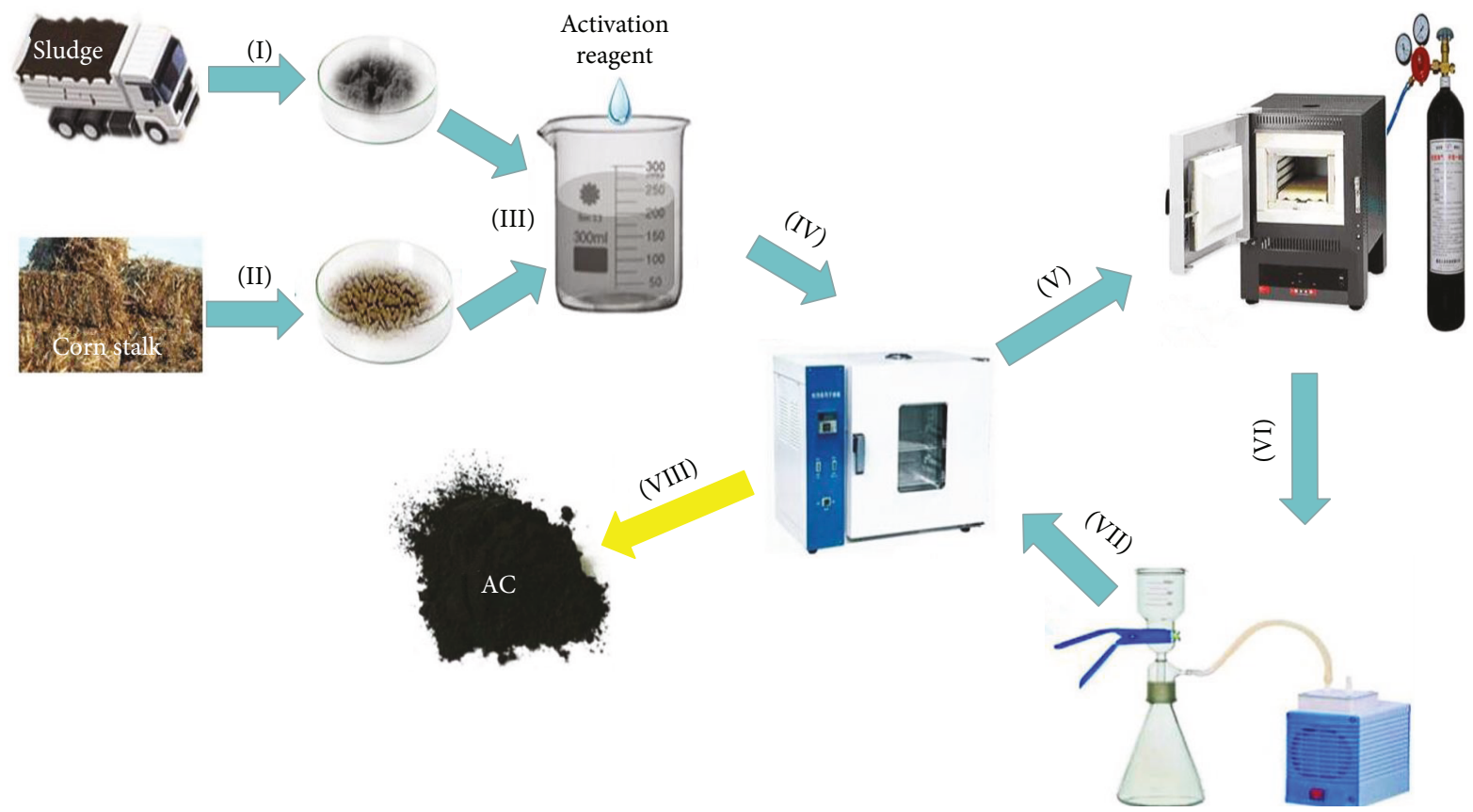

FIGURE 2: The preparation of SBAC using corn stalks mixing with sludge by chemical activation method [40].

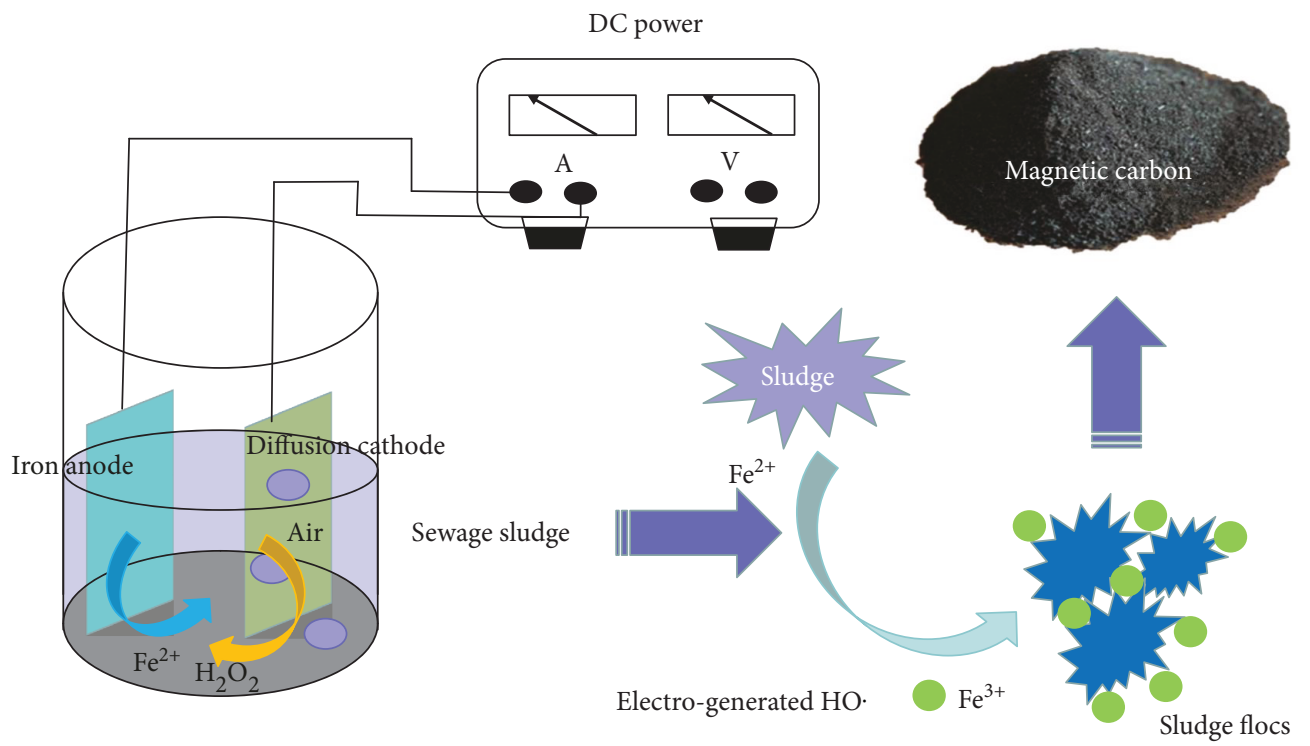

FIgURE 3: The preparation of EF-SBAC [44].

The SBAC modification methods can be divided into surface physical modification and surface chemical modification. The structural characteristics of SBAC can be observed by instrumental analysis such as scanning electron microscope (SEM), Fourier infrared transform spectrum, X-ray diffraction and X-ray photoelectron spectroscopy, and other parameter analyses such as BET surface area analysis denoted as BET analysis in this paper.

3.1. Surface Physical Modification. The physical structure modification of SBAC is mainly to increase the capacity of SBAC adsorption, which is affected by BET size, pore size, internal volume structure of micropore and volume capacity, micropore distribution on its surface, and so on [45-48]. To prepare an efficient SBAC having high BET value and wide and uniform pore distribution, we usually modify its surface structure by temperature activation, time adjustment, and oxidation corrosion of chemical reagent. The SBAC effectiveness can be improved significantly by the specific modification of SBAC but the selection of modification method is related to removal of pollutant. The SBAC adsorption characteristic was performed when the molecular size of pollutants was less than or equal to aperture of SBAC, and then the pollutant enters inside the aperture and absorbed and 


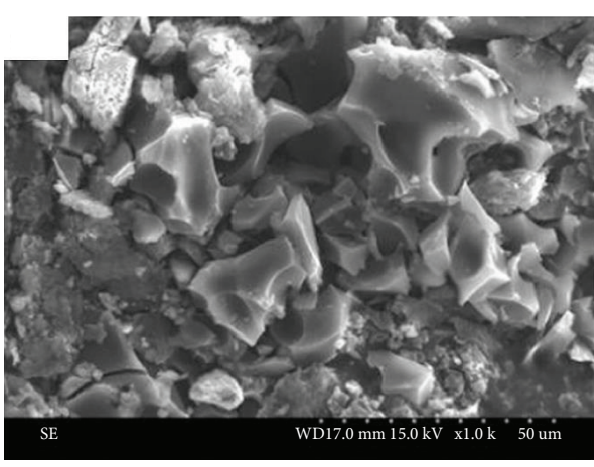

(a)

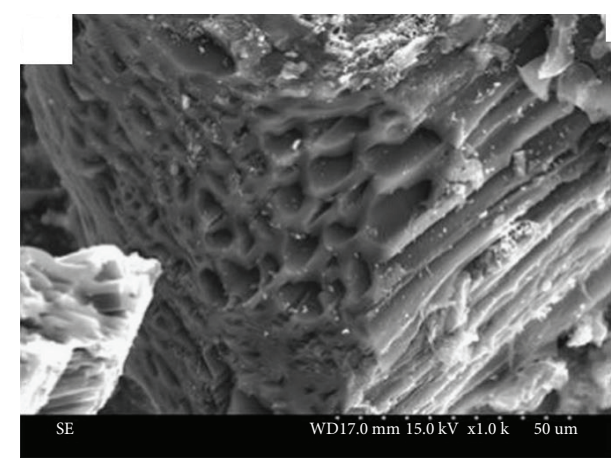

(b)

FIgURE 4: (a) The SEM images of SBAC (a) without corn bar; (b) with corn stalk [40].

separated [49]. In the process of carbonization and activation of SBAC, the physical structure of SBAC was significantly affected by external physical conditions and modifier [50]. Li et al. [40] added $25 \%$ corn stalk into the sludge using $4 \mathrm{~mol} / \mathrm{L} \mathrm{ZnCl}_{2}$ as activator, with the activation temperature at $600^{\circ} \mathrm{C}$ and pyrolysis time at $60 \mathrm{~min}$, to prepare a SBAC, which had a BET value as high as $769.0 \mathrm{~m}^{2} / \mathrm{g}$. As shown in Figures 4(a) and 4(b), it showed that the SEM images of SBAC after modification through hybriding corn stalk changed. The modified SBAC had an obvious longitudinal deep-hole structure evenly distributed on the surface. In the process of sludge pyrolysis, $\mathrm{ZnCl}_{2}$ can promote the secondary pyrolysis, reducing the formation of tar and promoting the dehydration of activated sludge and aromatization of organic matter [51]. The iron salt can effectively improve the pore structure of SBAC and improve the SBAC adsorption performance [52-54]. Jin et al. [55] showed that iron additive as catalyzer during activation was added into sludge, which could accelerate the reaction between carbon and high thermal water vapor and the pore structure adjustment of SBAC. $\mathrm{Su}$ et al. [56] added iron salts to the sludge to prepare costeffective iron-containing porous carbon (Fe-SBAC). The pyrolysis mixture of sludge and iron salts was favorable for adsorption of lead. With specific surface area, total pore volume, and average pore width of $321 \mathrm{~m}^{2} / \mathrm{g}, 0.25 \mathrm{~cm}^{3} / \mathrm{g}$, and $3.17 \mathrm{~nm}$, respectively, it resulted in the hydroxyl groups and carboxyl groups significantly. Fe-SBAC adsorption capacity can be as high as $128.9 \mathrm{mg} / \mathrm{g}$, while the adsorption capacity of activated carbon is $79.1 \mathrm{mg} / \mathrm{g}$.

The performance of SBAC was significantly affected by carbonization time and carbonization temperature. Because the sources of raw materials are different, the preparation temperature of SBAC required to reach maximum BET would be also different. For example, Jeyaseelan and Lu [57] showed that in the carbonization process, the best temperature is $850^{\circ} \mathrm{C}$; Inguanzo et al. [58] found that the best temperature was $650^{\circ} \mathrm{C}$; Bagreev et al. [59] indicated that $950^{\circ} \mathrm{C}$ was the suitable temperature; Rio et al. [60] had the best temperature fixed at $1000^{\circ} \mathrm{C}$. When Fan et al. [61] added chitosan to modify SBAC, it was found that both carbonization time and carbonization temperature could change BET value and pore volume of SBAC. Compared with the carbonization time, carbonization temperature had a much more significant influence. Silva et al. [62] heated sludge materials at room temperature till $300^{\circ} \mathrm{C}$ for 2 hours in the presence of $\mathrm{N}_{2}$ flow. With temperature elevated to a different level $\left(750^{\circ} \mathrm{C}, 800^{\circ} \mathrm{C}\right.$ and $\left.800^{\circ} \mathrm{C}\right)$ and activation under $\mathrm{CO}_{2}$ flow for $1 \mathrm{~h}$, different kinds of SBAC were prepared. It showed that the performance of SBAC was different by varying activation temperature.

Using chemical reagent activation treatment can modify BET and pore volume of SBAC and increase its adsorption efficiency. Linru et al. [63] showed that an increase in the size of BET and pore of SBAC occurred after nitric acid modification. The possible reason for the increase was that the oxidation corrosion of $\mathrm{HNO}_{3}$ destroyed the inner channel structure, which broke through the small pore and increased the surface area. Daoxiong [64] found that the use of nitric acid, ammonia, or hydrogen peroxide could improve the physical surface properties of SBAC, especially the treatment of ammonia, which could improve the pore diameter structure and increased the volume of micropore. Zhai et al. [65] studied the $\mathrm{HNO}_{3}$ and $\mathrm{NH}_{3}$ modification influence in the physical properties of the SBAC surface. The results showed that the $\mathrm{BET}$ of SBAC increased and the total pore volume and the pore volume also increased. The maximum BET and pore volume of SBAC prepared at $750 \mathrm{C}$ were $258 \mathrm{~m}^{2} / \mathrm{g}$ and $0.198 \mathrm{~cm}^{3} / \mathrm{g}$, respectively. Yang et al. [54] used iron as activator and pyrolyzed biological sludge to prepare SBAC, as shown in Figure 5. It shows that pyrolysis temperature and mass ratio (activator/dry sludge) significantly affected the BET value and pore characteristics of SBAC. It was included that iron activation could promote the development of the porous structure of SBAC; the best preparation condition for the pyrolysis temperature was $750^{\circ} \mathrm{C}$ and the mass ratio (activator/dry sludge) was 0.5 .

The washing of different solutions on the sludge affects the surface physical structure of SBAC as shown in Table 1. Alvarez et al. [66] studied the washing influence of hydrochloric acid and sodium carbonate in the SBAC prepared under carbon dioxide activation. During the whole activation process, the carbon content of pretreated sludge with hydrochloric acid and sodium carbonate decreased, while the content of ash increased. The increase of ash content was more obvious after pretreatment of sodium carbonate. 


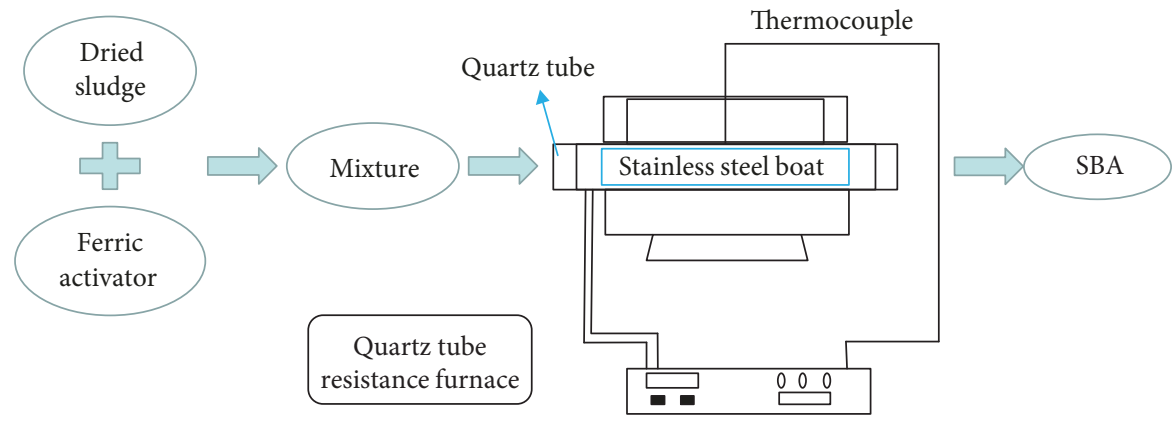

FIgURE 5: The preparation of SBAC using activated iron [54].

TABLE 1: Surface physicochemical characteristics of SBAC generated with pretreatment by different substances.

\begin{tabular}{|c|c|c|c|}
\hline Substance & $\operatorname{SBET}\left(\mathrm{m}^{2} \cdot \mathrm{g}^{-1}\right)$ & Surface property change & Reference \\
\hline $\mathrm{KOH}$ & 984 & $\begin{array}{l}\text { SBAC (KOH-800) is mainly mesoporous. The SBET and total pore volume of } \\
\text { SBAC are the closest to those of commercial Ac (the BET surface and total pore } \\
\text { volume of the commercial AC were } 984 \mathrm{~m}^{2} / \mathrm{g} \text { and } 0.663 \mathrm{~cm}^{3} / \mathrm{g} \text {, resp.). }\end{array}$ & [18] \\
\hline $\mathrm{NaOH}$ & 179 & $\begin{array}{l}\text { After modification with } \mathrm{NaOH} \text {, the shape of } \mathrm{SBAC} \text { is mesoporous and macroporous, } \\
\text { showing a stronger adsorption capacity for } \mathrm{CO}_{2} \text { than that of commercial Ac. }\end{array}$ & {$[67]$} \\
\hline $\mathrm{HCl}$ & 269 & $\begin{array}{l}\text { After the sludge was acid washed with } \mathrm{HCl}(5 \mathrm{M}) \text {, slight pore development was observed } \\
\text { and the BET surface area is } 269 \mathrm{~m}^{2} \cdot \mathrm{g}^{-1} \text { when activated under } \mathrm{CO}_{2} \text { at } 800^{\circ} \mathrm{C} \text {. }\end{array}$ & [19] \\
\hline $\mathrm{H}_{3} \mathrm{PO}_{3}$ & $<5$ & $\begin{array}{c}\text { Chemical activation with } \mathrm{H}_{3} \mathrm{PO}_{4} \text { was ineffective for an efficient porosity development in } \\
\text { the SBAC preparation process. }\end{array}$ & {$[19]$} \\
\hline $\mathrm{Na}_{2} \mathrm{CO}_{3}$ & 440 & $\begin{array}{l}\text { The } \mathrm{Na}_{2} \mathrm{CO}_{3} \text { washing step significantly promotes the development of the porous structure } \\
\text { in } \mathrm{CO}_{2} \text { activation of the treated char. }\end{array}$ & {$[66]$} \\
\hline
\end{tabular}

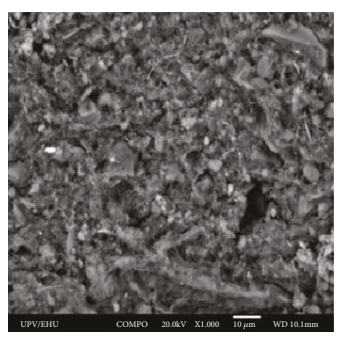

(a)

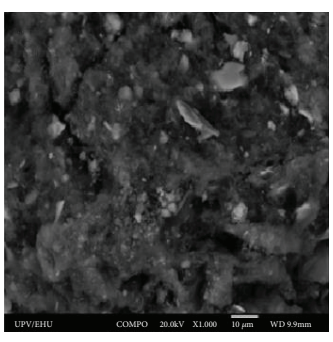

(b)

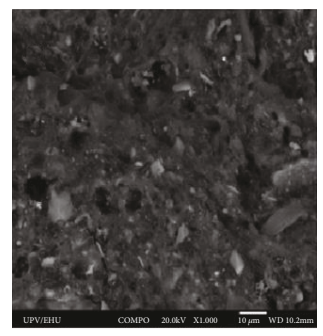

(c)

FIGURE 6: The SEM images of sludge: rapid pyrolysis (a); precursors after pickling (b); sodium carbonate treatment (c) [66].

The difference of surface characteristics by varying pretreatment reagents is shown in Figure 6.

3.2. Surface Chemical Modification. SBAC surface chemical modification is to change the chemical properties of the surface of SBAC and control the hydrophilicity and hydrophobicity of the adsorption process and the binding capacity between SBAC and pollutant. The activation methods often contain acid activation, alkali activation, and salt activation, and the activators mainly include $\mathrm{ZnCl}_{2}$ [68], $\mathrm{H}_{3} \mathrm{PO}_{4}$ [69], $\mathrm{NaOH}$ [70], $\mathrm{KOH}$ [71], and $\mathrm{H}_{2} \mathrm{SO}_{4}$ [72]. There are different types of functional groups formed on the surface of SBAC if using different types of activators, such as alkaline functional groups, acidic functional groups, oxygencontaining functional groups, and nitrogen-containing functional groups. The coupling of various activation methods can improve SBAC adsorption efficiency and overcome the defect of single activation [73]. At present, the SBAC surface chemical modification has been widely used, but there is still a deficiency of corrosivity in the chemical activation method. Table 2 illustrates the typical methods for preparing SBAC by surface chemical modification.

The acid modification and alkaline modification of SBAC can enhance its adsorption performance. Huijun et al. [86] used zinc chloride activation and nitric acid to modify SBAC. The result showed that the nitric acid modification can greatly improve the performance of SBAC. The organic matter and inorganic matter decomposition of sludge evaporated more completely, providing more functional groups which was a better adsorption to $\mathrm{Cd}^{2+}$. Lu et al. [87] studied the catalytic oxidation of chlorobenzoic acid (p-cba) with two kinds of SBAC which were modified by $\left(\mathrm{NH}_{4}\right)_{2} \mathrm{~S}_{2} \mathrm{O}_{8}$ and $\mathrm{NaOH}$. The study showed that the removal effects of two kinds of SBAC were significantly different. The main reason for the 


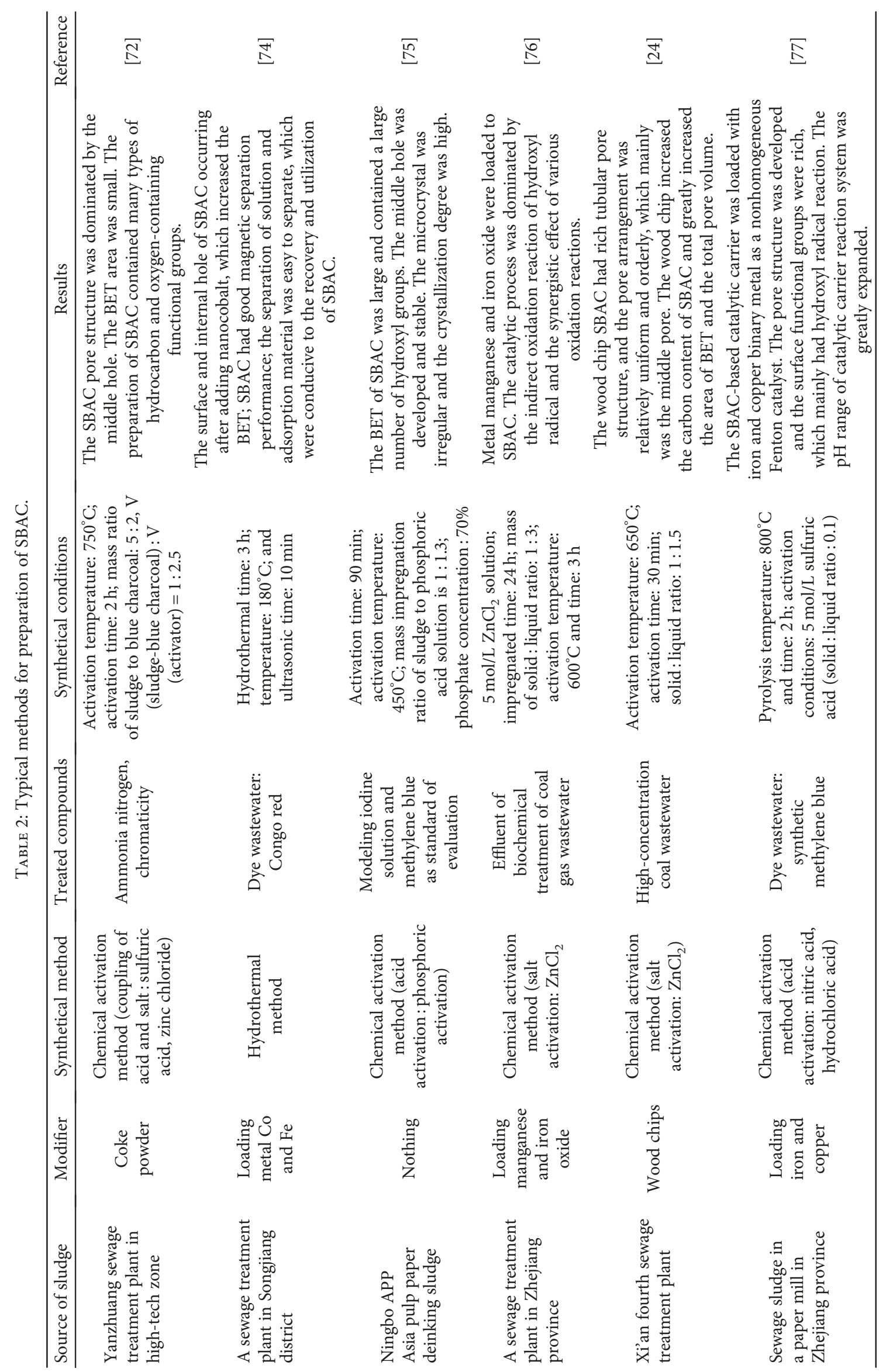




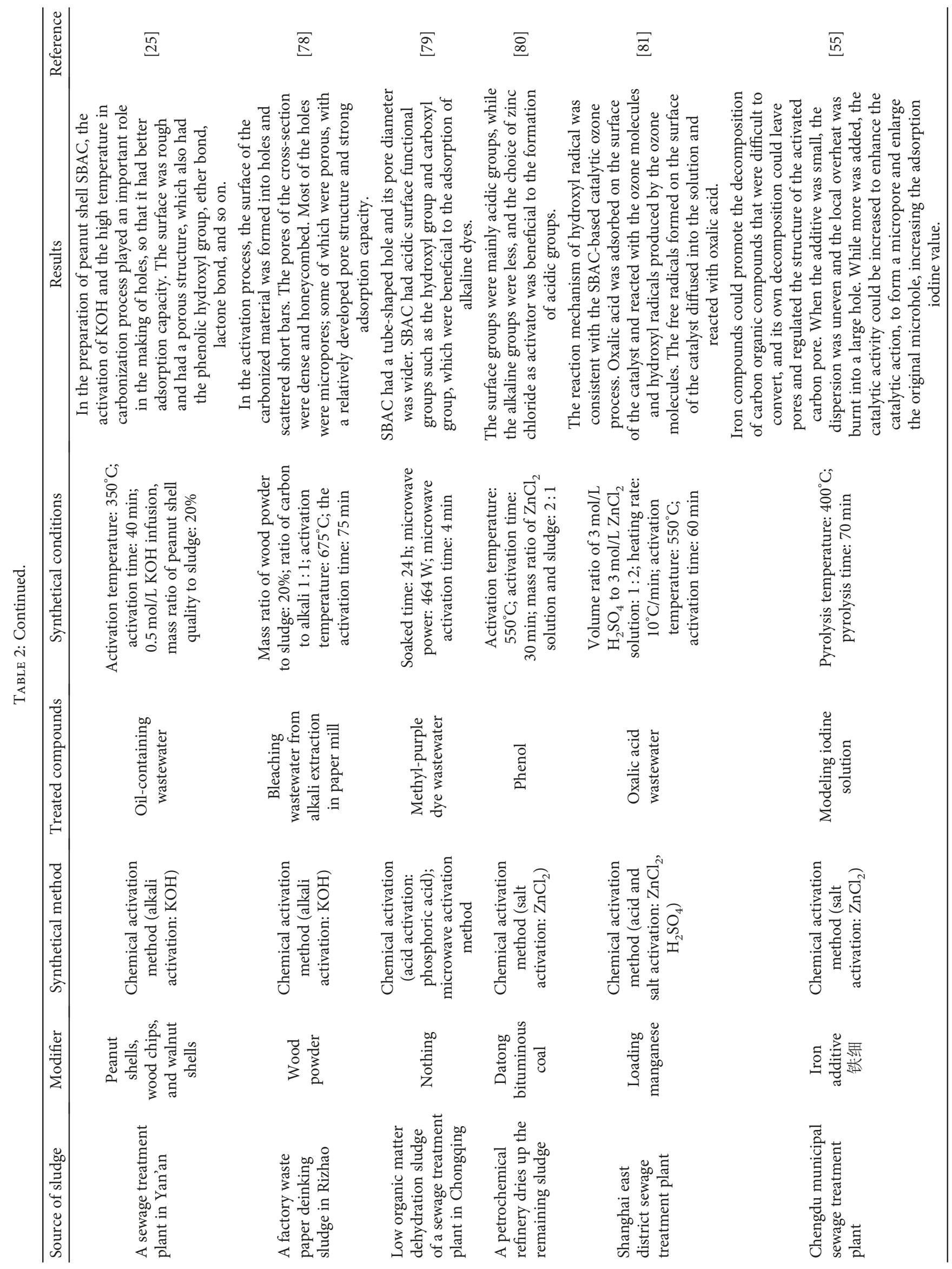




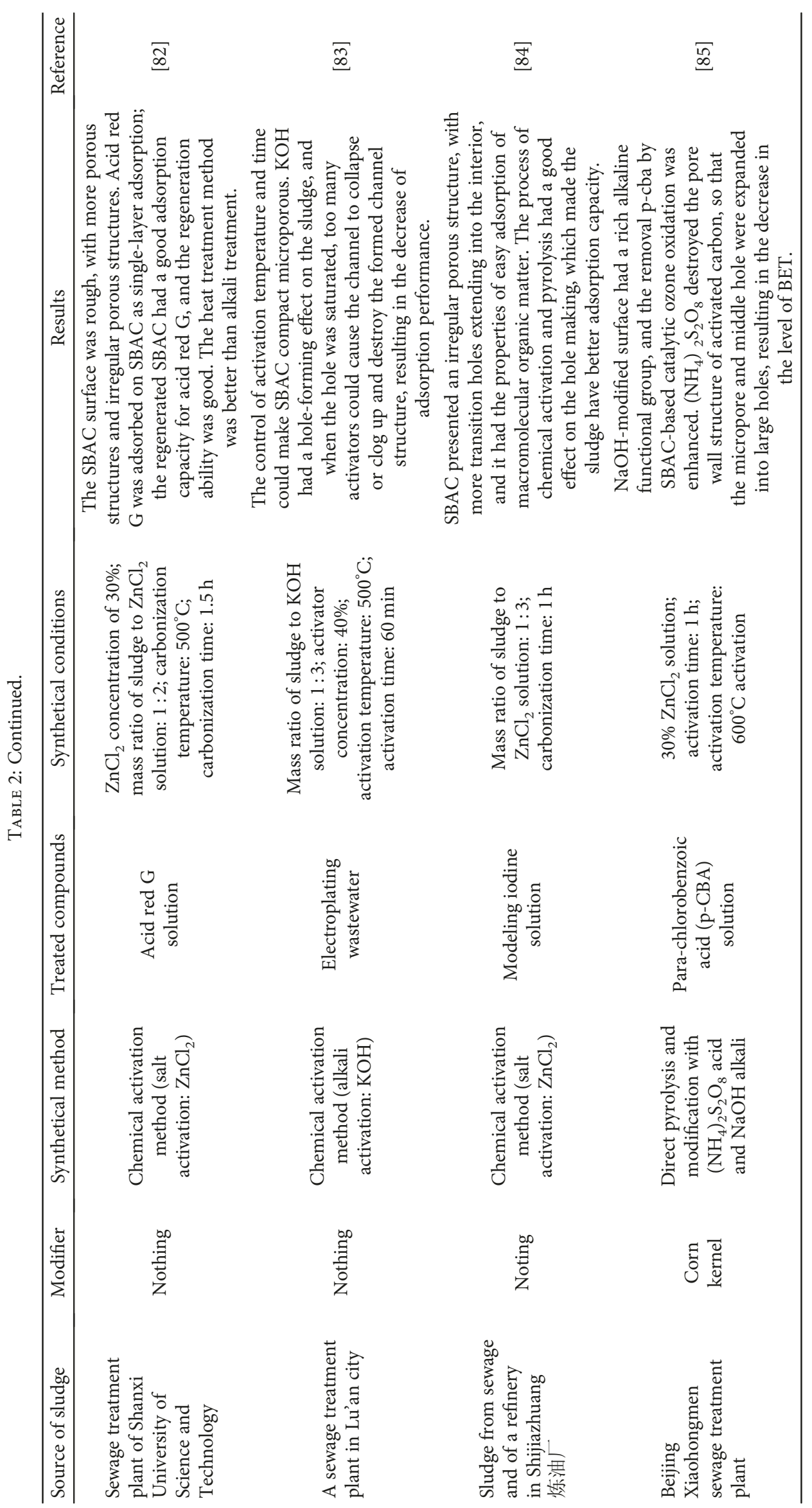


difference was that $\mathrm{NaOH}$ could enrich the alkaline functional groups of SBAC; thus, the efficiency of the catalytic ozone oxidation on removal of $\mathrm{p}$-cba could be improved.

The adsorption capacity of SBAC is related to not only the molecular size of SBAC but also the hydrophilicity and hydrophobicity between SBAC and pollutant. Karin and Li [88] studied the SBAC adsorption effect on eight hydrophobic organic compounds (HOCs) that were often detected in rainwater. Kinetic studies showed that most of the HOCs were absorbed within 10 minutes. In the batch test, the adsorption capacity was negatively correlated with the hydrophobicity of the compounds and positively associated with decreasing molecule size, suggesting that molecular sieving limited adsorption. However, in the repeated adsorption test, the competition between HOCs was more likely to occur, and the pollutant adsorption loading was positively correlated with the hydrophobicity of the compounds. Din et al. [89] used sludge and waste oil sludge to prepare bulk adsorbents for dealing with eleven antibiotics in a batch experiment. The variety of antibiotics was adsorbed on the surface of the sludge owing to its high degree of heterogeneity linked to the pores of specific sizes of hydrophobic nature and existence of the reactive/polar phase that dispersed in the pore walls. This ensured not only the accessibility of the high energy adsorption centers but also the possibility of precipitation of surface reaction products within the pore system.

The chemical activation of new activators can enhance the mesoporous structure of SBAC effectively, which also promotes the interaction of SBAC with pollutants. Yang et al. [54] showed that in a batch experiment, the ironactivated SBAC had higher adsorption capacity than the unactivated SBAC. The iron activation enhanced the mesoporous structure to facilitate the diffusion of tetracycline into the pore, and the iron oxide and oxygen-containing functional groups of SBAC could be complexed on the surface, resulting in a good effect on adsorption of pollutants. The functional groups generated by surface chemical modification can be removed by electrostatic force resulting from the adsorbed ions. Al-Malack and Dauda [90] put activated sludge under the activation temperature of $700^{\circ} \mathrm{C}$ for 60 mins, using $5 \mathrm{M} \mathrm{ZnCl}_{2}$ as activator, and the prepared SBAC had a BET of $319.5 \mathrm{~m}^{2} / \mathrm{g}$. At the same time, the mechanism for adsorption of $\mathrm{Cd}^{2+}$ was also studied, showing that the $\mathrm{Cd}^{2+}$ was mainly removed by the electrostatic adsorption between the functional group with negative charge on the surface of SBAC and the positively charged metal ions. The negatively charged hydroxy or carboxyl group on the surface of SBAC played a major role in the removal of $\mathrm{Cd}^{2+}$.

In the process of chemical modification of SBAC, there would appear specific metal complexes and oxygencontaining functional groups can form strong bonds with adsorbent materials. Hanyu et al. [91] used reed straw and activated sludge as raw materials to prepare SBAC under the condition of $500^{\circ} \mathrm{C}$ and to study its adsorption effect on the removal of norfloxacin. The results showed that there were lots of oxygen-containing functional groups in SBAC, which provided adsorption sites for the adsorption of norfloxacin. The presence of oxygen-containing functional groups was conducive to the formation of strong hydrogen bonds between norfloxacin and SBAC, where the hydrogen bond played a dominant role in SBAC adsorption of norfloxacin. Therefore, the chemical functional groups can enhance the adsorption capacity of SBAC. Xin et al. [92] adopted the $\mathrm{ZnCl}_{2}$ activation method to prepare SBAC, which showed that the content of $\mathrm{Al}$ and $\mathrm{Fe}$ in the oxidation form in the SBAC was higher than that of commercial active carbon, which can enhance the adsorption of SBAC to organic matter in water. Fan et al. [61] prepared SBAC with chitosan, which contained a large amount of nitrogen and oxygen-containing functional groups. The types and quantities of the desulfurization and denitration active groups in the surface of SBAC were enriched, which could help the adsorption and the oxidation of $\mathrm{SO}_{2}$ and NO. Also, adding chitosan could significantly increase SBAC properties such as the BET value and the middle-hole volume. As a result, the physical adsorption of $\mathrm{SO}_{2}$ and $\mathrm{NO}$ gas was then increased, thus improving its desulfurization and denitration performance under the appropriate condition control. Zou et al. [93] prepared a clean sludge (P-SBAC) which did not contain inorganic impurities (e.g., Si and $\mathrm{Al}$ ) in activated sludge. The morphological characteristics, surface elements, and functional groups of SBAC were different from P-SBAC: P-SBAC had a BET and pore volume ratio of about 3 times more than that of SBAC; the oxygen-containing groups of hydroxyl and epoxide in P-SBAC were rich, which were conductive to the removal of organic pollutants from the wastewater. Furthermore, the P-SBAC had better adsorption effects in the removal of rhodamine $\mathrm{B}$ and phenolic compounds.

\section{Applications}

4.1. Organic Matter Removal. The chemical sludge containing a large amount of iron and aluminum oxide was modified to prepare SBAC, of which the effect on the removal of $\mathrm{UV}_{254}$ and dissolved organic carbon is similar to the activated carbon. SBAC's removal rate of $\mathrm{UV}_{254}$ and dissolved organic carbon could be up to $85.8 \%$ and $59.7 \%$ [94], respectively. The possible organics that can be treated with SBAC also contain toluene [95], phenol [96], nitrobenzene [97], trinitrotoluene [98], rhodamine B [99], and ibuprofen (IBP) [100]. Table 3 shows the mechanism of removing these organic matters, mainly through physic-chemical adsorption and hydroxyl radical oxidation.

The SBAC that was prepared with activated sludge mixing with other substances in a certain proportion is of higher organic adsorption performance. Xin et al. [101] prepared the SBAC using dehydrated sludge as raw materials and an appropriate amount of sawdust and coconut shell, which was activated by $\mathrm{ZnCl}_{2}$. The dynamic adsorption experiment of toluene showed that in the initial concentration of the same toluene, the equilibrium adsorption efficiencies were listed in a descending order: shell SBAC, coal-activated carbon, and sawdust-activated carbon. The prepared SBAC showed better adsorption performance. During the analysis of SBAC physical and chemical properties, the mesoporic and chemical adsorption was helpful to the increase in the level of adsorption. Lijun and Wenju [98] used the 
TABLE 3: Organic compound removal by SBAC: preparation methods and removal mechanisms.

\begin{tabular}{|c|c|c|c|}
\hline Organic compounds & Methods & Mechanisms & Reference \\
\hline Toluene & $\mathrm{ZnCI}_{2}$ dipping, $700^{\circ} \mathrm{C}$ activation & $\begin{array}{l}\text { Middle-pore adsorption in physics and chemical } \\
\text { adsorption }\end{array}$ & {$[101]$} \\
\hline Phenol, nitrobenzene & Mix of sludge and corn & Chemical acid group adsorption mainly & {$[22]$} \\
\hline Trinitrotoluene red water & $\begin{array}{l}\text { Phosphoric acid-microwave method, } \\
\text { chemical modification }\end{array}$ & $\begin{array}{l}\text { The surface of large hole, internal extension of more } \\
\text { transition hole, physical adsorption mainly }\end{array}$ & [98] \\
\hline Rhodamine B & $\begin{array}{l}\text { Biological sludge and chemical } \\
\text { sludge compound }\end{array}$ & $\begin{array}{l}\text { The reaction of the catalytic ozone oxidation of } \\
\text { rhodamine B following the hydroxyl radical mechanism }\end{array}$ & {$[102]$} \\
\hline Ibuprofen & $\begin{array}{l}\text { Zinc chloride prepared SBAC } \\
\text { as an activator }\end{array}$ & Hydroxyl radical mechanism and physical adsorption & {$[103]$} \\
\hline Oxalic acid & MnOx load modification & $\begin{array}{l}\text { Surface reaction, reaction between organic pollutants } \\
\text { and hydroxyl radical }\end{array}$ & {$[104]$} \\
\hline
\end{tabular}

phosphoric acid microwave method to prepare a kind of SBAC which had a large surface and abundant extension holes and studied the adsorption of SBAC to three nitrotoluene red water. The results showed that when the adsorption equilibrium time was $60 \mathrm{~min}$ and the total volume was $8 \%$, the removal rate of dichromate oxidizability (CODcr) was $85.7 \%$, of which the purification effect was better than activated carbon. Daojing et al. [22] obtained a SBAC with different proportions of corn cores and studied its adsorption to phenol and nitrobenzene. The study showed that the higher doping proportion of the corn cob, the larger the activated carbon micropore volume and the larger BET and the SBAC surface was dominated by acidic groups.

The SBAC can also be used as a catalyst or catalyst carrier to provide conditions for the preparation of new composite photocatalytic materials, and the synergetic effect of adsorption and catalysis in removal of pollutants was exhibited significantly $[105,106]$. The $\mathrm{MnOx} / \mathrm{SBAC}$ prepared by Huang et al. [104] has good catalytic activity. In the heterogeneous catalytic ozonation process of oxalic acid mineralization, its catalytic activity was better than single SBAC and the reaction mechanisms include surface reaction and hydroxyl radical reactions, but the surface reaction played a dominant role. Haifeng et al. [107] adopted the impregnation method to load the transition metal manganese and iron oxide onto the SBAC surface, which significantly increased the efficiency of ozone oxidation wastewater pollutants. Under optimal ozonation, the catalyst increased the ozone utilization rate by $40 \%$ and operation cost significantly.

The principles of removing organic matter may be different due to different modification methods. Hongjuan et al. [103] prepared SBAC with zinc chloride as an activator and dehydrating sludge and corn cob as raw materials. The reaction mechanisms were different in different stages of catalytic ozone oxidation of IBP. In the instantaneous oxygen-phase reaction, the mechanisms were based on the reaction of $\mathrm{OH}$ and IBP; in the slow reaction stage, it is mainly based on SBAC adsorption. Yangyang et al. [102] mixed biological sludge and chemical sludge together to obtain a SBAC, which follows the hydroxyl radical oxidation mechanism in the catalytic ozone oxidation of rhodamine B. Gu et al. [108] studied the properties of $\mathrm{Fe}_{3} \mathrm{O}_{4}$-separable magnetic porous carbon (F-SBAC) that were synthesized by a new type of activation and carbonation process without additional iron ions. The properties of F-SBAC synthesized at $600^{\circ} \mathrm{C}, 800^{\circ} \mathrm{C}$, and $1000^{\circ} \mathrm{C}$ were studied by $\mathrm{N}_{2}$ adsorption and desorption isotherm. F-SBAC has a high surface area $\left(407.7 \mathrm{~m}^{2} / \mathrm{g}\right)$ and a porous structure at $600^{\circ} \mathrm{C}$. F-SBAC600, F-SBA800, and FSBA1000 achieved 96.6\%, 67.5\%, and 38.9\% removal rates of 1,2,4-acid. Compared with the degradation efficiency of commercially available nanomagnetic $\mathrm{Fe}_{3} \mathrm{O}_{4}$ (57.5\%), FSBAC600 showed an excellent performance to catalyze hydrogen peroxide to produce hydroxyl radicals. Sun et al. [109] studied metal-free catalyst activation sulfate peroxide, with urea as additional nitrogen source; the nitrogenfunctionalized carbon sludge (N-SBAC) was prepared. The nitrogen functionalization of the N-SBAC significantly affects the chemical microenvironment as well as the microstructure (morphology and porosity), which can be effectively oxidized to remove organic contaminant.

The surface functional groups of SBAC were removed by electron donor-receptor reaction. Gupta and Garg [110] reported that the mechanism of SBAC adsorption to phenol is usually based on the electron donor receptor reaction between the aromatic phenolic rings and the functional groups on the surface of the SBAC. Al-Malack and Dauda [90] prepared a SBAC which was characterized by FTIR, indicating the existence of hydroxyl and carboxyl groups on the surface of SBAC. The reason for the decrease of adsorption capacity of SBAC to $\mathrm{Cd}^{2+}$ in the presence of phenol may be the competition of adsorption sites of two components on the surface of SBAC. It may also be attributed to the space resistance of the adsorbent phenol on the surface of SBAC. The removal efficiency of phenol was enhanced in the presence of $\mathrm{Cd}^{2+}$. That may be related to the stable effect of the SBAC surface adsorption of $\mathrm{Cd}^{2+}$ ions, which made the surface functional groups interact freely with the phenol ring molecules. Kong et al. [111] showed that the citric acid- $\mathrm{ZnCl}_{2}$-mixed fabricating pore agent was a potential technique in green production of sludge-derived char with hierarchical porous for reuse of sludge. The sludge-derived char was considered as a hybrid material containingelemental carbon, highly aromatic organic species and inorganic ash. Many kinds of benzene derivatives in aqueous solution could be treated. Multiple sorption including pore filling, hydrophobic interaction, and the stronger specific 
sorption bindings between carboxyl and $\mathrm{SiO}_{2}$ can be presented in the sorption of the porous sludge char towards carboxyl-containing adsorbates. Nunthaprechachan et al. [112] studied the effect of dibenzothiophene (DBT) removal from n-octane by a SBAC prepared with the sewage sludge of doping chemical reagents $\left(\mathrm{ZnCl}_{2}, \mathrm{HNO}_{3}\right.$, and $\left.\mathrm{KOH}\right)$. With the increase of oxygen-containing functional groups, especially carbonyl groups, DBT adsorption increased. SBAC prepared by $\mathrm{KOH}$ activation showed the highest adsorption capacity, up to $14.12 \mathrm{mg} / \mathrm{g}$ or about $70.6 \%$ DBT removal, which was about $1.22-1.28$ times more than that of the commercial activated carbon.

4.2. Heavy Metal Removal. The removals of heavy metal ions with SBAC were mainly achieved through ion exchange reaction, chemical adsorption, and physical adsorption. Heavy metal ions can generate an exchange reaction on the surface of activated carbon. The surface of SBAC can be introduced to the special groups to strengthen the absorption of heavy metal ions after adding a reagent or remodification of SBAC. These surface groups form ligands with heavy metal ions and their type and stability can determine the adsorption quantity and adsorption capacity of SBAC. The SBAC adsorption of heavy metals is mainly chemical adsorption. Heavy metal ions are combined with surface functional groups thus forming adsorption products.

The adsorption mechanisms for heavy metal removal by SBAC consist of surface precipitation and ion exchange [113]. Tan et al. [113] prepared SBAC under $900^{\circ} \mathrm{C}$ by anaerobic pyrolysis. This SBAC has good adsorption to $\mathrm{Pb}, \mathrm{Zn}, \mathrm{Cu}$, and $\mathrm{Cd}$, and its adsorption capacity is higher than that of commercial activated carbon. When $\mathrm{pH}$ was buffered to a fairly high level, the heavy metal ions were converted into hydroxide and precipitated on the surface of SBAC. When $\mathrm{pH}$ was low, in addition to producing a very small amount of precipitation, a large number of heavy metal ions were exchanged with $\mathrm{Ca}^{2+}$ and subsequently adsorbed by SBAC.

The SBAC surface chemical functional groups could react with heavy metal ions as chemical adsorption, in which the acid groups of the SBAC surface can form stable ligands with heavy metal ions. Hanfeng. [114] studied the process of adsorbing heavy metals by SBAC containing loaded functional groups. The BET and micropore volume ratio of SBAC are smaller than those of coir and coal, and in addition, SBAC has a low adsorption rate. However, the equilibrium adsorption efficiencies of $\mathrm{Cu}$ (II), $\mathrm{Pb}$ (II), Cr (VI), and Cd (II) are much higher than that of commercial activated carbon, which is possibly attributed to the fact that the content of the acid group in SBAC is too high that it affects the adsorption of heavy metal ions. Weiwei et al. [115] studied the adsorption effect on the removal of $\mathrm{Cu}$ (II) and $\mathrm{Pb}$ (II) with SBAC prepared by zinc chloride activation and commercial coal carbon. It showed that the BET and pore volume of SBAC were accounted for by the $36.7 \%$ and $23.6 \%$ of commercial coal carbon, respectively. But on the surface, there was a high content of the acid functional group, its equilibrium adsorbate uptake on $\mathrm{Cu}$ (II) and $\mathrm{Pb}$ (II) was much higher than that of commercial coal carbon.
Heavy metal ions that are sedimented on the surface of activated carbon are physically adsorbed. The physical adsorption of heavy metal ions in SBAC mainly occurred on the surface. With the elapse of the adsorption process, the adsorption mass gradually got through the bigger hole and transition pores and finally arrived at the micropore. The mass transfer velocity of heavy metal ions gradually became slow among the inner bore, which eventually reached adsorption equilibrium with adsorption capacity increased gradually over time $[116,117]$. Tao et al. [118] prepared a SBAC with sludge and bagasse as raw materials through pyrolysis under $800^{\circ} \mathrm{C}$ for 0.5 hours. After treatment with $60 \% \mathrm{HNO}_{3}, \mathrm{BET}$ could be up to $806.57 \mathrm{~m}^{2} / \mathrm{g}$. The changes to pore diameter indicated that $\mathrm{HNO}_{3}$ oxidation could enhance the adsorption capacity of metal ions.

The SBAC in the removal of heavy metals can also be coupled with the other processes. Qing et al. [119] used activated sludge as raw materials to obtain SBAC through carbonization preparation. They used the impregnationsintering method to load nano- $\mathrm{TiO}_{2}$ on SBAC, obtained $\mathrm{TiO}_{2} / \mathrm{AC}$ photocatalyst, and studied its removal effect on heavy metal ion $\mathrm{Hg}^{2+}$. The results showed that the adsorption performance and catalytic efficiency of $\mathrm{TiO}_{2} / \mathrm{AC}$ photocatalyst were high and the $\mathrm{Hg}^{2+}$ removal rate of $20 \mathrm{mg} / \mathrm{L}$ aqueous solution was $88.5 \%$.

4.3. Gas Pollutant Removal. SBAC has the characteristics of uniform small particles, even pore distribution, high BET, and so on, whose surface loads a certain amount of active component. Its functional groups are rich, crystal surface content increases, and the crystal structure becomes more orderly [120]. Those are beneficial to contact with the reaction gas. Qingbo et al. [121] studied the formaldehyde adsorption properties of SBAC and commercial activated carbon. The results showed that SBAC contained a large number of ultramicropore, micropores, and various nitrogen-containing groups, which form a chemical adsorption center, which were conductive to the adsorption of low-concentration formaldehyde. SBAC has a good adsorption effect on formaldehyde in the air, and the maximum removal rate can reach up to $83 \%$, which is the same with that of commercial activated carbon. SBAC can be used as an important carrier, loading catalyst for removing organic matter. Tao [122] studied the effect of SBAC loading nitric acid iron sludge-based catalyst on $\mathrm{NO}_{\mathrm{X}}$ gas, and the maximum conversion rate of $\mathrm{NO}_{\mathrm{X}}$ was 98.3\%. Yanjing [123] took SBAC as the carrier of the $\mathrm{TiO}_{2}$ photocatalyst, and the $\mathrm{TiO}_{2} / \mathrm{SBAC}$ photocatalytic degradation of acetone gas achieved good results.

Wei et al. [124] adopted $\mathrm{ZnCl}_{2}$ to prepare SBAC as an active agent, which was modified with cerium. It was utilized in $\mathrm{H}_{2} \mathrm{~S}$ removal. Their study showed that the SBAC deodorization performance was greatly improved, no matter modified by cerium doping or loading. After modification, the SBAC surface was still the middle hole, but its aperture was smaller and the surface functional group increased, making it more favorable for $\mathrm{H}_{2} \mathrm{~S}$ material adsorption and catalytic reaction, which was beneficial to $\mathrm{H}_{2} \mathrm{~S}$ gas removal. Boualem et al. [17] used sludge to chemically react with phosphoric 
acid to prepare SBAC. The surface area of the activated carbons was at $300 \mathrm{~m}^{2} / \mathrm{g}$. The activated carbons were mainly mesoporous. $\mathrm{SO}_{2}$ adsorption capacity was associated with average micropore size, which could be controlled by the impregnation ratio used to prepare the activated carbons.

4.4. Others. The SBAC not only can be used alone but also can be coupled with other water treatment technologies to increase its application prospect thus reducing the operational cost. The BET of SBAC prepared by Dezhi et al. [125] was $397.9 \mathrm{~m}^{2} / \mathrm{g}$. Combining it with membrane bioreactor to treat the waste leachate, SBAC could improve the properties and structure of the cake layer on the membrane surface, so that the membrane had higher filtration performance and water permeability. It has the advantages of reducing membrane fouling and protein as well as humic acid, lengthening membrane operation cycle, and lowering operation costs. Zhai et al. [126] studied the effect of SBAC on sludge liquefaction. It showed that SBAC was conducive to the increase of the yield and energy density of bio-oil at $350^{\circ} \mathrm{C}$ (denoted as 350-SBAC at this temperature). 350SBAC was beneficial to lowering the risk of $\mathrm{Cu}, \mathrm{Zn}$, and $\mathrm{Pb}$, while 400-SBAC was effective in lowering the risk of Cd, $\mathrm{Cu}$, and $\mathrm{Zn} .400^{\circ} \mathrm{C}$ was preferable for lowering the risk of $\mathrm{SR}$, while special attention needs to be paid to $\mathrm{Cd}$. Considering the bio-oil yield, the use of liquefaction at $350^{\circ} \mathrm{C}$ with SSAC-550 was preferable.

4.5. Regeneration of SBAC. Recycling of activated carbon is of great significance for environmental protection and resource conservation. Regeneration of SBAC is the use of physical and chemical means to restore the adsorption capacity of SBAC saturated with various pollutants without destroying the original activated carbon structure. At present, the regenerative technologies of activated carbon mainly include the thermal regeneration method [127], wet oxidation regeneration method [128], microwave regeneration method [129], and high-frequency ultrasonic regeneration method [130]. For a lower regeneration cost and an available regeneration cycle, the selection of the methods for adsorption, degradation, and regeneration is bound to be affected by the types and properties of pollutants. Recycling of sludge activity should take into account the cost of recycling and repreparation of sludge-activated carbon, the loss of activated carbon during regeneration, regenerative adsorption capacity, secondary pollution, and other issues. For sludge-activated carbon adsorption material recovery, based on the nature of the material being adsorbed, to determine the recovery method, the regeneration mechanism of sludge-based activated carbon needs to be further explored. The safety issues during regeneration are worth considering. Parts of the regeneration methods are still in the experimental stage and can not be widely applied to production practice.

\section{Summary}

Sewage treatment produce a lot activated sludge. If the sludge is prepared into SBAC, it can reduce environmental pollution and bring considerable economic value. Compared with the traditional activated carbon, the preparation cost of SBAC is lower and there is a wide range of source. Therefore, the research and application of SBAC have potential value. At present, the research and application of SBAC have obtained a certain achievement. However, some problems still remain to be solved in the preparation and application of SBAC, which needs further process. First, potential release of some toxic and hazardous substances during the preparation and preparation of SBAC were produced. For example, the heavy metals are possible to be released from SBAC. The transformation and its mechanisms for soluble heavy metal into insoluble metal compound are still not clear in preparation of SBAC. Second, the environmental effects of SBAC need to be further studied such as the disposal of waste SBAC, the leakage of its adsorbed substance in the transfer, the effective recycle and reuse of SBAC adsorption materials, the regeneration technology, and regeneration performance comparison between SBAC and commercial activated carbon. Third, the reaction mechanisms for SBAC preparation need deeper study. Because of the complexity of sludge composition and the influence including pyrolysis conditions and pyrolysis equipment and other factors, in the preparation process of activation, the organic matters in activated sludge can produce chemical reaction due to the activation by temperature. Meanwhile, the additives and chemical activators make chemical reaction more complicated. Therefore, studying the variations of the activation process and activation mechanism can give us guidance in the preparation, modification, and application of SBAC at a deeper level.

\section{Conflicts of Interest}

The authors declare that there is no conflict of interests regarding the publication of this paper.

\section{Acknowledgments}

The authors gratefully acknowledge the financial support from the National Natural Science Foundation of China (no. 51408215), Natural Science Foundation of Hunan Province of China (no. 2018JJ2128), China Postdoctoral Science Foundation (no. 2017M622578), Research Foundation of Hunan University of Science and Technology (nos. E51508 and KJ1808), and Hunan Province Innovation Project Foundation of Graduate Students, China (CX2017B638).

\section{References}

[1] S.-J. Yuan and X.-H. Dai, "Sewage sludge-based functional nanomaterials: development and applications," Environmental Science: Nano, vol. 4, no. 1, pp. 17-26, 2017.

[2] T. Li, Y. L. Wang, J. Feng, and M. Xu, "Relationship between physicochemical characteristics of activated sludge and polymer conditioning dosage," Huanjing kexue, vol. 33, no. 3, pp. 889-895, 2012.

[3] L. Xiong-wei, L. Jun, L. Chong et al., "Current application situation and development trend of sludge treatment and disposal technologies in China," China Water and Wastewater, vol. 32, pp. 26-30, 2016. 
[4] S. Haiyong, "Resource utilization of municipal sludge," Clean Coal Technology, vol. 21, pp. 91-94, 2015.

[5] F. Cheng, H. Luo, L. Hu, B. Yu, Z. Luo, and M. Fidalgo de Cortalezzi, "Sludge carbonization and activation: from hazardous waste to functional materials for water treatment," Journal of Environmental Chemical Engineering, vol. 4, no. 4, pp. 4574-4586, 2016.

[6] Y. Xin, "Research on preparation and application of sewage sludge-based adsorbent," Harbin Institute of Technology, 2011.

[7] G. Xu, X. Yang, and L. Spinosa, "Development of sludgebased adsorbents: preparation, characterization, utilization and Its feasibility assessment," Journal of Environmental Management, vol. 151, pp. 221-232, 2015.

[8] M. Tie, H. Yeli, and Y. Xinming, "Preparation of activated carbon and Its application progress," Jianghan Univevsity, vol. 41, pp. 5-12, 2013.

[9] S. Ruinhua, F. Ping, and S. Quanyin, "Research on preparation of activated carbon from sewage sludge," Journal of Anhui Agricultural Sciences, vol. 38, pp. 17632-17635, 2010.

[10] K. M. Smith, G. D. Fowler, S. Pullket, and N. J. D. Graham, "Sewage sludge-based adsorbents: a review of their production, properties and use in water treatment applications," Water Research, vol. 43, no. 10, pp. 2569-2594, 2009.

[11] V. Calisto, C. I. A. Ferreira, S. M. Santos, M. V. Gil, M. Otero, and V. I. Esteves, "Production of adsorbents by pyrolysis of paper mill sludge and application on the removal of citalopram from water," Bioresource Technology, vol. 166, pp. 335-344, 2014.

[12] D. Hui, Y. Le, L. WuDaoyong, and L. Z. Yuqi, "Preparation and properties of sludge adsorbents by phosphoric acid activation- microwave pyrolysis method," Journal of Shihezi University:Natural Science, vol. 34, pp. 85-91, 2016.

[13] Y. Hong, Z. Shichao, S. Yan, and Y. Xin, "Preparation and characterization of sludge activated carbon," Chinese Journal of Environmental Engineering, vol. 6, pp. 2138-2142, 2012.

[14] V. M. Monsalvo, A. F. Mohedano, and J. J. Rodriguez, "Adsorption of 4-chlorophenol by inexpensive sewage sludge-based adsorbents," Chemical Engineering Research and Design, vol. 90, no. 11, pp. 1807-1814, 2012.

[15] Y. Zhu, J. Gao, Y. Li et al., "Preparation of activated carbons for $\mathrm{SO}_{2}$ adsorption by $\mathrm{CO}_{2}$ and steam activation," Journal of the Taiwan Institute of Chemical Engineers, vol. 43, pp. 112-119, 2012.

[16] Z. Wang, X. Ma, Z. Yao, Q. Yu, Z. Wang, and Y. Lin, "Study of the pyrolysis of municipal sludge in $\mathrm{N}_{2} / \mathrm{CO}_{2}$ atmosphere," Applied Thermal Engineering, vol. 128, pp. 662-671, 2018.

[17] T. Boualem, A. Debab, A. Martínez de Yuso, and M. T. Izquierdo, "Activated carbons obtained from sewage sludge by chemical activation: gas-phase environmental applications," Journal of Environmental Management, vol. 140, pp. 145-151, 2014.

[18] M. Hunsom and C. Autthanit, "Adsorptive purification of crude glycerol by sewage sludge-derived activated carbon prepared by chemical activation with $\mathrm{H}_{3} \mathrm{PO}_{4}, \mathrm{~K}_{2} \mathrm{CO}_{3}$ and $\mathrm{KOH}$," Chemical Engineering Journal, vol. 229, pp. 334-343, 2013.

[19] A. Ros, M. A. Lillo-Ródenas, E. Fuente, M. A. Montes-Morán, M. J. Martín, and A. Linares-Solano, "High surface area materials prepared from sewage sludge-based precursors," Chemosphere, vol. 65, no. 1, pp. 132-140, 2006.

[20] M. J. Puchana-Rosero, M. A. Adebayo, E. C. Lima et al., "Microwave-assisted activated carbon obtained from the sludge of tannery-treatment effluent plant for removal of leather dyes," Colloids and Surfaces A: Physicochemical and Engineering Aspects, vol. 504, pp. 105-115, 2016.

[21] J. A. Menéndez, M. Inguanzo, and J. J. Pis, "Microwaveinduced pyrolysis of sewage sludge," Water Research, vol. 36, no. 13, pp. 3261-3264, 2002.

[22] L. Daojing, F. Li, and Z. Liqiu, "Effects of corncob addition on properties of sludge activated carbon," Chinese Journal of Environmental Engineering, vol. 6, pp. 1010-1014, 2012.

[23] C. Wu, M. Song, B. Jin, Y. Wu, and Y. Huang, "Effect of biomass addition on the surface and adsorption characterization of carbon-based adsorbents from sewage sludge," Journal of Environmental Sciences, vol. 25, no. 2, pp. 405$412,2013$.

[24] D. Jingqi, L. Yongjun, Z. Lu, and L. Yu, "Preparation of activated carbon with dewatered sludge and its application in semi-coking wastewater treatment," Chinese Journal of Environmental Engineering, vol. 10, pp. 6337-6342, 2016.

[25] L. Yu, L. Yu, C. Qian et al., "Preparation of peanut hull sludge-based activated carbon and application for oily wastewater treatment," Environmental Pollution \& Control, vol. 38, no. 9, pp. 43-47, 2016.

[26] B. Zhao, X. Xu, H. Li, X. Chen, and F. Zeng, "Kinetics evaluation and thermal decomposition characteristics of copyrolysis of municipal sewage sludge and hazelnut shell," Bioresource Technology, vol. 247, pp. 21-29, 2018.

[27] Z. Jingjing, "Study on preparation of sludge activated carbon and its application," South China University of Technology, 2013.

[28] S. Ruihua and F. Ping, "Pyrolysis kinetics of activated sewage sludge in preparation of sewage sludge-based activated carbon," The Chinese Journal of Process Engineering, vol. 13, pp. 217-223, 2013.

[29] W. Zhangxie, C. Mingqing, W. Jun, C. Minggong, and M. Fanxia, "Study on characteristics and kinetics of pyrolysis process of rice husk," Journal of Anhui University of Science \& Technology, vol. 29, pp. 43-46, 2009.

[30] W. Hongliang, S. Chongdian, and G. Qingjie, "Preparation and characterization of the activated carbon produced with sewage sludge," Shandong Chemical Industry, vol. 37, pp. 1-5, 2008.

[31] W. Yimin, H. Yaji, S. Mi, and J. Baosheng, "Study on preparation of activated carbon made from sludge by steam activation," China Environmental Science, vol. 32, pp. 640-646, 2012.

[32] Z. Peitao, G. Shifu, and L. Changyan, "Activated carbon production from sewage sludge employing low-oxygen flue gas," Transactions of the Chinese society of Agricultural Engineering, vol. 29, pp. 215-222, 2013.

[33] R. Xiaoli and Z. Kaijin, "Preparation of sludge-derived adsorbent by dry pyrolysis and its process optimization research," Chemical Industry \& Engineering Progress, vol. 32, pp. 29973001, 2013.

[34] Y. Bingkui, Z. Shiqing, Z. Nanwen, Y. Shuibo, and S. Zongqi, "Research on preparation of activated carbon from sludge by chemical activation method and its application," China Water \& Wastewater, vol. 22, pp. 88-90, 2006. 
[35] S. Xin, H. Xuemin, and C. Li, "Sludge active carbon prepared by wet process of chemical activation and its applied reserch, Shanghai," Environmental Sciences, vol. 32, pp. 25-30, 2013.

[36] G. S. dos Reis, M. Wilhelm, T. C. d. A. Silva et al., "The use of design of experiments for the evaluation of the production of surface rich activated carbon from sewage sludge via microwave and conventional pyrolysis," Applied Thermal Engineering, vol. 93, pp. 590-597, 2016.

[37] Q. H. Lin, H. Cheng, and G. Y. Chen, "Preparation and characterization of carbonaceous adsorbents from sewage sludge using a pilot-scale microwave heating equipment," Journal of Analytical and Applied Pyrolysis, vol. 93, pp. 113-119, 2012.

[38] A. B. Namazi, D. Grant Allen, and C. Q. Jia, "Microwaveassisted pyrolysis and activation of pulp mill sludge," Biomass and Bioenergy, vol. 73, pp. 217-224, 2015.

[39] L. Yanan, Y. Liying, and Y. Xiaoyang, "Preparation of straw carbon by $\mathrm{ZnCl}_{2}$-microwave method," Chemical World, vol. 56, pp. 337-339, 2015.

[40] Y. Li, Y. Li, L. Li, X. Shi, and Z. Wang, "Preparation and analysis of activated carbon from sewage sludge and corn stalk," Advanced Powder Technology, vol. 27, no. 2, pp. 684-691, 2016.

[41] X. Ren, B. Liang, M. Liu, X. Xu, and M. Cui, "Effects of pyrolysis temperature, time and leaf litter and powder coal ash addition on sludge-derived adsorbents for nitrogen oxide," Bioresource Technology, vol. 125, pp. 300-304, 2012.

[42] W. Yachen, G. Lin, W. Miaoli, L. Ziyang, Z. Nanwen, and Y. Haiping, "Preparation of the sludge based activated carbon with Fenton oxidation pretreatment and its property," Environmental Pollution \& Control, vol. 36, pp. 43-48, 2014.

[43] L. Gu, Y. Wang, N. Zhu et al., "Preparation of sewage sludge based activated carbon by using Fenton's reagent and their use in 2-naphthol adsorption," Bioresource Technology, vol. 146, pp. 779-784, 2013.

[44] L. Gu, C. Li, H. Wen et al., "Facile synthesis of magnetic sludge-based carbons by using electro-Fenton activation and its performance in dye degradation," Bioresource Technology, vol. 241, pp. 391-396, 2017.

[45] Y. Lanlan, Z. Qin, and F. Lanlan, "Research on preparation of activated carbon adsorbent from sewage sludge and its application," Journal of Safety \& Environment, vol. 5, pp. 39-42, 2005.

[46] L. Gang, "Study on preparation of sewage sluge based activated carbon and its application in adsorption of $\mathrm{Pb}^{2+}$," Harbin Institute of Technology, 2012.

[47] L. Gang, L. Weiguang, W. Guangzhi, L. Xin, and G. Xujin, "Preparation and characterization of sludge activated carbon and its application," Environmental Engineering, vol. 30, pp. 489-493, 2012.

[48] S. Wei, Y.-P. Zhou, L.-F. Wei, Y. Sun, and L. Zhou, "Effect of microstructure and surface modification on the hydrogen adsorption capacity of active carbons," New Carbon Materials, vol. 22, no. 2, pp. 135-140, 2007.

[49] Y. Yuan, "Regularity of partical size of activated carbon on the adsorption of organic pollutants with different molecular weight and research in biological effluent treatment," Kunming University of Science and Technology, 2013.

[50] R. Ailing, W. Qishan, and G. Bin, "Structure characterization and surface fractal analysis of sludge activated carbon," Acta Chimica Sinica, vol. 64, pp. 1068-1072, 2006.
[51] L. Xin, "The research on the prepation of sludge based activated carbon based on $\mathrm{ZnCl}_{2}$ activation method and its role in mitigating membrane fouling MBR," Harbin Institute of Technology, 2014.

[52] X. Yang, G. Xu, and H. Yu, "Removal of lead from aqueous solutions by ferric activated sludge-based adsorbent derived from biological sludge," Arabian Journal of Chemistry, 2016.

[53] Q. Yang, X. Wang, W. Luo et al., "Effectiveness and mechanisms of phosphate adsorption on iron-modified biochars derived from waste activated sludge," Bioresource Technology, vol. 247, pp. 537-544, 2018.

[54] X. Yang, G. Xu, H. Yu, and Z. Zhang, "Preparation of ferricactivated sludge-based adsorbent from biological sludge for tetracycline removal," Bioresource Technology, vol. 211, pp. 566-573, 2016.

[55] S. Jin, Y. Yijin, L. Yu, X. Xin, T. Xiandong, and Z. Xinyu, "Effects of Fe-containing additives on performance and structure of sludge activated carbon," Journal of Qingdao University of Science and Technology(Natural Science Edition), vol. 37, pp. 654-659, 2016.

[56] Y. Su, X. Sun, X. Zhou, C. Dai, and Y. Zhang, “Zero-valent iron doped carbons readily developed from sewage sludge for lead removal from aqueous solution," Journal of Environmental Sciences, vol. 36, pp. 1-8, 2015.

[57] S. Jeyaseelan and G. Q. Lu, "Development of adsorbent/ catalyst from municipal wastewater sludge," Water Science \& Technology, vol. 34, no. 3-4, pp. 499-505, 1996.

[58] M. Inguanzo, J. A. Menéndez, E. Fuente, and J. J. Pis, "Reactivity of pyrolyzed sewage sludge in air and $\mathrm{CO}_{2}$," Journal of Analytical and Applied Pyrolysis, vol. 58-59, pp. 943-954, 2001.

[59] A. Bagreev, T. J. Bandosz, and D. C. Locke, "Pore structure and surface chemistry of adsorbents obtained by pyrolysis of sewage sludge-derived fertilizer," Carbon, vol. 39, no. 13, pp. 1971-1979, 2001.

[60] S. Rio, C. Faur-Brasquet, L. le Coq, D. Lecomte, and P. le Cloirec, "Preparation and characterization of activated carbon from sewage sludge: carbonization step," Water Science \& Technology, vol. 49, no. 1, pp. 139-146, 2004.

[61] X. Fan, X. Zhang, and T. Xu, "Desulfurization and denitrification properties of activated carbon from sewage sludge modified by chitosan," Acta Scientiae Circumstantiae, vol. 32, pp. 1750-1756, 2012.

[62] T. L. Silva, A. Ronix, O. Pezoti et al., "Mesoporous activated carbon from industrial laundry sewage sludge: adsorption studies of reactive dye Remazol rilliant Blue R," Chemical Engineering Journal, vol. 303, pp. 467-476, 2016.

[63] F. Linru, Z. Liguo, L. Lei et al., "Adsorptive property of $\mathrm{Cr}$ ( VI) by modified sludge-based adsorbent with foaming agent," Journal of South China Normal University (Natural Science Edition), vol. 47, pp. 50-54, 2015.

[64] P. Daoxiong, Preparation of Sewage Sludge-Based Activated Carbon by Nitrogen-Functionalizaton and its Application in Perchlorate Removal, Hunan University, 2014.

[65] Y. Zhai, D. Pang, H. Chen et al., "Effects of ammonization on the surface physico-chemical properties of sludge-based activated carbon," Applied Surface Science, vol. 280, pp. 590597, 2013.

[66] J. Alvarez, G. Lopez, M. Amutio, J. Bilbao, and M. Olazar, "Preparation of adsorbents from sewage sludge pyrolytic char 
by carbon dioxide activation," Process Safety and Environmental Protection, vol. 103, Part A, pp. 76-86, 2016.

[67] J. M. de Andrés, L. Orjales, A. Narros, M. d. M. de la Fuente, and M. E. Rodríguez, "Carbon dioxide adsorption in chemically activated carbon from sewage sludge," Journal of the Air \& Waste Management Association, vol. 63, no. 5, pp. 557-564, 2013.

[68] T. Xuemei, J. Fangying, F. Min, G. Wei, P. Yi, and L. Xiangdan, "Preparation and fractal research of activated carbon from sludge with $\mathrm{ZnCl}_{2} / \mathrm{CuCl}_{2}$ as activating agent," Environmental Engineering, vol. 30, pp. 85-88, 2012.

[69] Z. Yanfei, "Adsorption of $\mathrm{Pb}(\mathrm{II})$ by activated carbon made from activated sludge using H3PO4 activation," Journal of Minnan Normal University(Natural Science), vol. 29, pp. 64-69, 2016.

[70] L. Xin, N. Xunan, L. Chaoping et al., "Optimization of preparation conditions for activated carbons from textile dyeing sludge and sawdust using response surface methodology based on CCD," Chinese Journal of Environmental Engineering, vol. 8, pp. 4937-4942, 2014.

[71] Z. Pin, G. Lin, R. Shanshan, H. Yongchun, Y. Haiping, and Z. Nanwen, "Preparation of sludge-straw based actived carbon and its adsorption for 1-diazo-2-naphtol-4-sulfonic acid," Environment and Chemistry, vol. 32, pp. 106-111, 2013.

[72] W. Aimin, B. Ni, Z. Guotao, W. Ruibin, and Y. Long, "Study on preparation of pressed active carbon based on sewage sludge and fine semi-coke and properties of adsorption," Fine Chemicals, vol. 34, pp. 207-213, 2017.

[73] Y. Lanlan, "Study on preparation of adsorbents made from sewage sludges and their application," Nanjing University of Science and Technology, 2006.

[74] D. Kaiyun, C. Haibing, X. H. ZhuXueyuan, and X. Yajun, "Study on the treatment of cyanobacteria by pellet flocculation and precipitation concentrated after being pressured," Technology of Water Treatment, vol. 43, pp. 29-33, 2017.

[75] C. Fujiang, L. Tingzhi, and L. Xiangxiang, "Preparation and characterization of mesoporous activated carbon prepared from deinking residue using phosphoric acid as activator," China Pulp \& Paper, vol. 36, pp. 36-41, 2017.

[76] Z. Haifeng, H. Hongjun, and S. Shengdao, "Advanced treatment of coal gasification wastewater using catalytic ozonation by sewage sludge based activated carbon as catalysts in pilotscale," Journal of Harbin Institute of Technology, vol. 49, pp. 85-91, 2017.

[77] G. Jinyi, Application Research of Paper Mill SludgeDerived Activated Carbon in Heterogeneous Fenton Reaction, Zhejiang University, 2016.

[78] Y. Zhongya, W. Junfen, W. Yuying, and Z. Xueming, "Preparation and characterization of activated carbon from deinking sludge activated by potassium hydroxide," Transactions of China Pulp and Paper, vol. 31, pp. 32-36, 2016.

[79] W. Chongjun, P. Yi, T. Xuemei et al., "On preparation and adsorption behavior of sludge activated-carbon derived from low content organics in the sludge," Journal of Southwest China Normal University(Natural Science Edition), vol. 41, pp. 159-163, 2016.

[80] H. Dongyan, L. Juan, J. Ping et al., "Activated carbon from biological sludge blended with bituminous coal: preparation and its phenol adsorption properties," Chinese Journal of Environmental Engineering, vol. 10, pp. 5931-5936, 2016.
[81] S. Yaru and H. Yuanxing, "Research on the catalytic ozonation of oxalic acid in wastewater with manganese loaded sludge activated carbon as catalyst, journal of water resources \& water," Engineering, vol. 27, pp. 101-107, 2016.

[82] W. Jiahong, Z. Di, Y. Xiaolong, and L. Shaochong, "Preparation of activated carbon from activated sludge and its adsorption behavior for acid scarlet G," Chinese Journal of Environmental Engineering, vol. 9, pp. 58-64, 2015.

[83] W. Xinlai, Y. Zhimin, W. Ke, W. Xiaodan, and W. Wenkui, "Preparation of activated carbon from dewatered sludge by chemical activation with $\mathrm{KOH}$," Applied Chemical Industry, vol. 44, pp. 463-465, 2015.

[84] Z. Wenxia, Z. Yanjing, H. Jing, R. Ailing, and L. Xi, "Preparation and characterization of activated carbons from refinery sludge and municipal sludge," Environmental Science d Technology, vol. 38, pp. 130-150, 2015.

[85] Z. Zili, Resource Utilization of Urban Sewage Sludge and Zinc Electroplating Sludge and their Adsorption and Catalytic Degradation for Methylene Blue, Shanghai University, 2015.

[86] H. Huijun, Y. Chunping, L. Shenglian, Z. Ying, and L. Lihua, "Adsorption of $\mathrm{Cd}(\mathrm{II})$ from aqueous solution by modified activated carbon made from activated sludge," Chinese Journal of Environmental Engineering, vol. 6, pp. 4034-4040, 2012.

[87] L. Lu, F. Li, and Z. Liqiu, "Influences of surface functional groups of sludge-corncob activated carbon on catalytic ozonation activity," Environment and Chemistry, vol. 33, pp. 937942, 2014.

[88] K. Björklund and L. Y. Li, "Adsorption of organic stormwater pollutants onto activated carbon from sewage sludge," Journal of Environmental Management, vol. 197, pp. 490-497, 2016.

[89] R. Ding, P. Zhang, M. Seredych, and T. J. Bandosz, “Removal of antibiotics from water using sewage sludge-and waste oil sludge-derived adsorbents," Water Research, vol. 46, no. 13, pp. 4081-4090, 2012.

[90] M. H. Al-Malack and M. Dauda, "Competitive adsorption of cadmium and phenol on activated carbon produced from municipal sludge," Journal of Environmental Chemical Engineering, vol. 5, no. 3, pp. 2718-2729, 2017.

[91] Z. Hanyu, W. Zhaowei, G. Junhong, Z. Junmin, X. Chaoran, and X. Xiaoyun, "Adsorption characteristics of norfloxacin by biochars derived from reed straw and municipal sludge," Huan Jing ke Xue= Huanjing Kexue, vol. 37, pp. 689-696, 2016.

[92] L. Xin, L. Weiguang, W. Guangzhi et al., "Preparation and properties of sludge-based activated carbon based on $\mathrm{ZnCl}_{2}$ activation method," Journal of Central South University(Science and Technology), vol. 44, pp. 4362-4370, 2013.

[93] J. Zou, Y. Dai, X. Wang et al., "Structure and adsorption properties of sewage sludge-derived carbon with removal of inorganic impurities and high porosity," Bioresource Technology, vol. 142, pp. 209-217, 2013.

[94] P. Zhihui, Z. Chaosheng, T. Jiayu, Z. Qing, and L. Guibai, "Application of chemical sludge based adsorbent in wastewater treatment," Water \& Wastewater Engineering, vol. 40, pp. 142-145, 2014.

[95] H. Xuemin, S. Xin, and Y. Quan, "Adsorption of toluene by fixed sludge-based activated carbon bed," Chinese Journal of Environmental Engineering, vol. 7, pp. 1085-1090, 2013. 
[96] F. Ping, S. Ruihua, and R. Juan, "Adsorption of phenol from aqueous solution using activated carbon," Carbon Techniques, vol. 30, pp. 12-16, 2011.

[97] L. Daojing, Study on Sludge Activated Carbon Preparation and Its Adsorption Properties of Phenol and Nitrobenzene, Beijing Forestry University, 2011.

[98] Y. Lijun and J. Wenju, "Adsorption of red-water from trinitrotoluene manufacturing by sludge-based adsorbent," Industrial Water \& Wastewater, vol. 36, pp. 26-28, 2005.

[99] H. Jiarong, "The Adsorption Study of Rhodamine-B by Activated Carbon of Activated Sludge," Journal of Minnan Normal University(Natural Science), pp. 83-87, 2016.

[100] W. Xue, Z. Liqiu, and F. Li, "Removal efficiency of ibuprofen and determination of active sites in catalytic ozonation process by modified SCACs," Chinese Journal of Environmental Engineering, vol. 9, pp. 621-626, 2015.

[101] S. Xin, H. Xue-min, C. Li, and Y. Quan, "Preparation of sludge-based activated carbon and adsorptive properties of toluene," Environmental Science \& Technology, vol. 35, pp. 32-35, 2012.

[102] Y. Yangyang, L. Xueqiang, X. Danyu, Z. Tao, S. Yan, and Y. Ang, "The catalytic ozonation of sludge-based composite activated carbon for the degradation of $\mathrm{Rh} \mathrm{B}$ in aqueous solution," Industrial Water Treatment, vol. 35, pp. 56-59, 2015.

[103] W. Hongjuan, Q. Fei, F. Li, and Z. Liqiu, "Catalytic ozonation of ibuprofen in aqueous solution by activated carbon made from sludge and corn cob," Environmental Science, vol. 33, pp. 1591-1596, 2012.

[104] Y. Huang, Y. Sun, Z. Xu, M. Luo, C. Zhu, and L. Li, "Removal of aqueous oxalic acid by heterogeneous catalytic ozonation with $\mathrm{MnO}_{\mathrm{x}} /$ sewage sludge-derived activated carbon as catalysts," Science of The Total Environment, vol. 575, pp. 5057, 2017.

[105] G. Wen, Z.-H. Pan, J. Ma, Z.-Q. Liu, L. Zhao, and J.-J. Li, "Reuse of sewage sludge as a catalyst in ozonation - efficiency for the removal of oxalic acid and the control of bromate formation," Journal of Hazardous Materials, vol. 239-240, pp. 381-388, 2012.

[106] H. Zhuang, H. Han, B. Hou, S. Jia, and Q. Zhao, "Heterogeneous catalytic ozonation of biologically pretreated Lurgi coal gasification wastewater using sewage sludge based activated carbon supported manganese and ferric oxides as catalysts," Bioresource Technology, vol. 166, pp. 178186, 2014.

[107] Z. Haifeng, "Research on efficiency of advanced treatment of coal gasification wastewater by catalytic ozonation integrated with biological process," Harbin Institute of Technology, 2015.

[108] L. Gu, N. Zhu, and P. Zhou, "Preparation of sludge derived magnetic porous carbon and their application in Fentonlike degradation of 1-diazo-2-naphthol-4-sulfonic acid," Bioresource Technology, vol. 118, pp. 638-642, 2012.

[109] H. Sun, X. Peng, S. Zhang et al., "Activation of peroxymonosulfate by nitrogen-functionalized sludge carbon for efficient degradation of organic pollutants in water," Bioresource Technology, vol. 241, pp. 244-251, 2017.

[110] A. Gupta and A. Garg, "Primary sewage sludge-derived activated carbon: characterisation and application in wastewater treatment," Clean Technologies and Environmental Policy, vol. 17, no. 6, pp. 1619-1631, 2015.
[111] L. Kong, Y. Xiong, L. Sun et al., "Sorption performance and mechanism of a sludge-derived char as porous carbonbased hybrid adsorbent for benzene derivatives in aqueous solution," Journal of Hazardous Materials, vol. 274, pp. 205-211, 2014.

[112] T. Nunthaprechachan, S. Pengpanich, and M. Hunsom, "Adsorptive desulfurization of dibenzothiophene by sewage sludge-derived activated carbon," Chemical Engineering Journal, vol. 228, pp. 263-271, 2013.

[113] C. Tan, H. Rong, W. Hongtao, L. Wenjing, Z. Yuancheng, and Z. Zeyu, "Adsorption of heavy metals by biochar derived from municipal sewage sludge," Journal of Tsinghua University, vol. 54, pp. 1062-1067, 2014.

[114] B. Hanfeng, Performance and Mechanism of four Kinds of Heavy Metals Removal from Water by Prepared SludgeBased Activated Carbon, Beijing Forestry University, 2013.

[115] Y. Weiwei, F. Li, and Z. Liqiu, "Preparation of columnar sludge-based activated carbon and its application in pollutants removal," Acta Scientiae Circumstantiae, vol. 34, pp. 385-391, 2014.

[116] F. Ziyan, Technological Research of Adsorption of Heavy Metals by Modified Activated Carbon, Tsinghua University, 2014.

[117] M. A. A. Zaini, M. Zakaria, N. Alias et al., "Removal of heavy metals onto $\mathrm{KOH}$-activated ash-rich sludge adsorbent," Energy Procedia, vol. 61, pp. 2572-2575, 2014.

[118] H. C. Tao, H. R. Zhang, J. B. Li, and W. Y. Ding, "Biomass based activated carbon obtained from sludge and sugarcane bagasse for removing lead ion from wastewater," Bioresource Technology, vol. 192, pp. 611-617, 2015.

[119] L. Qing, R. Xueying, and L. Jiali, "The ${ }_{p}$ reparation of titanium dioxide photocatalyst loaded on the modified products of municipal sewage sludge," Guangdong Chemical Industry, vol. 39, pp. 59-60, 2012.

[120] Z. Yifan and B. Kangsheng, "Study on the adsorption characteristic of formaldehyde in the air by modified PSAC," AnHui Chemical Industry, vol. 43, pp. 33-37, 2017.

[121] W. Qingbo, L. Caiting, C. Zhihong, Z. Wei, and G. Hongliang, "Application of sewage sludge based activated carbon in formaldehyde adsorption," China Environmental Science, vol. 30, pp. 727-732, 2010.

[122] L. Tao, PreParation and ProPerties of Nitrogen Oxide Catalyst Derived from Sewage Sludge, Hunan University, 2007.

[123] Z. Yanjing, "Study on preparation of TiO2/sludge activated carbon and its photocatalytic purification of acetone gas," Hebei University of Science \& Technology, 2015.

[124] J. Wei, Z. Linhuan, L. Fen, Y. Bo, and J. Anxi, "Study on preparation and performance of cerium modified active carbon adsorbent from sewage sludge," Materials Review, vol. 30, pp. 411-414, 2016.

[125] L. Dezhi, W. Guangzhi, L. Xin, and W. Ping, "Study on membrane fouling properties in treatment of landfill leachate by SBAC/MBR process," China Water \& Wastewater, vol. 31, pp. 21-26, 2015.

[126] Y. Zhai, H. Chen, B. Xu et al., "Influence of sewage sludgebased activated carbon and temperature on the liquefaction of sewage sludge: yield and composition of bio-oil, immobilization and risk assessment of heavy metals," Bioresource Technology, vol. 159, pp. 72-79, 2014.

[127] E. Zhou, Y. He, X. Ma et al., "Study of the combination of sulfuric acid treatment and thermal regeneration of spent 
powdered activated carbons from decolourization process in glucosamine production," Chemical Engineering and Processing: Process Intensification, vol. 121, pp. 224-231, 2017.

[128] B. Ledesma, S. Román, E. Sabio, and A. Álvarez-Murillo, "Improvement of spent activated carbon regeneration by wet oxidation processes," The Journal of Supercritical Fluids, vol. 104, pp. 94-103, 2015.

[129] N. M. Nor, M. F. F. Sukri, and A. R. Mohamed, "Development of high porosity structures of activated carbon via microwave-assisted regeneration for $\mathrm{H}_{2} \mathrm{~S}$ removal," Journal of Environmental Chemical Engineering, vol. 4, no. 4, Part B, pp. 4839-4845, 2016.

[130] Z. Sun, C. Liu, Z. Cao, and W. Chen, "Study on regeneration effect and mechanism of high-frequency ultrasound on biological activated carbon," Ultrasonics Sonochemistry, vol. 44, pp. 86-96, 2018. 


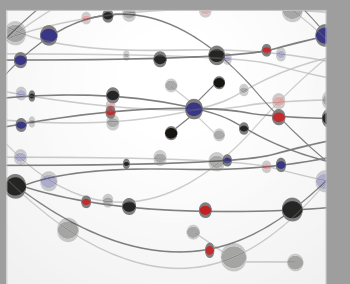

The Scientific World Journal
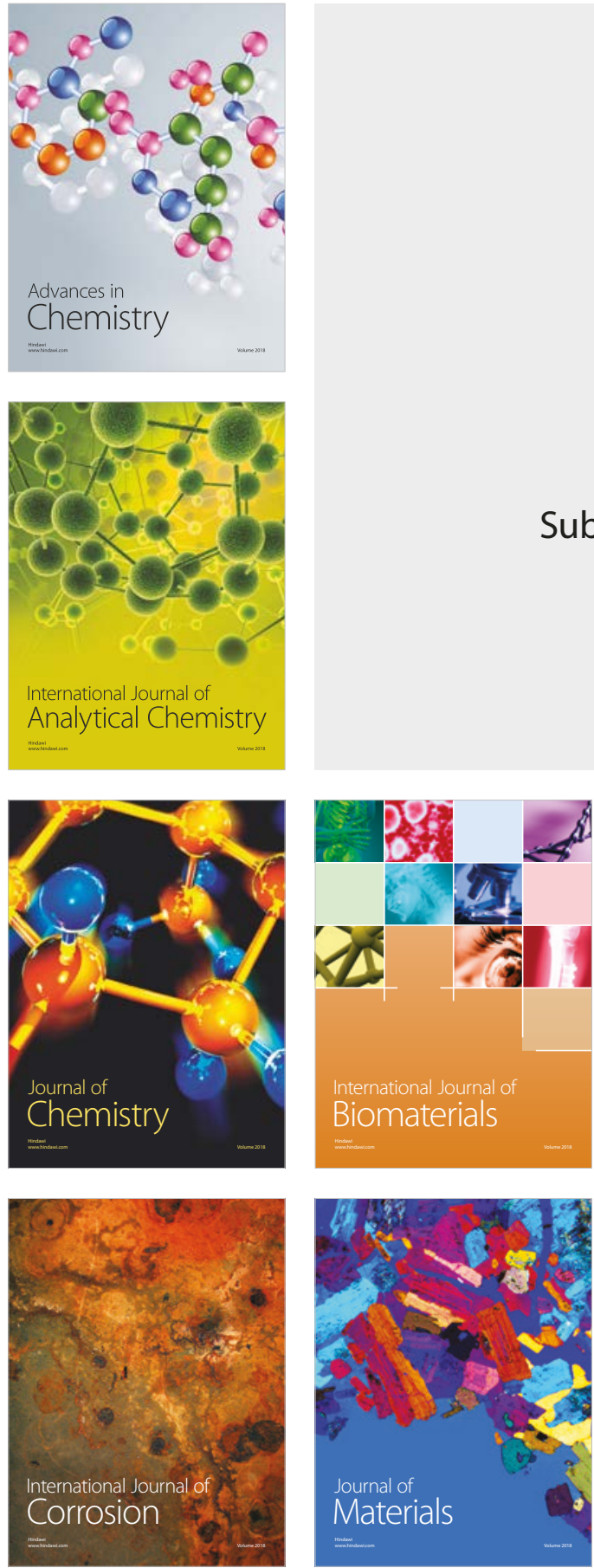

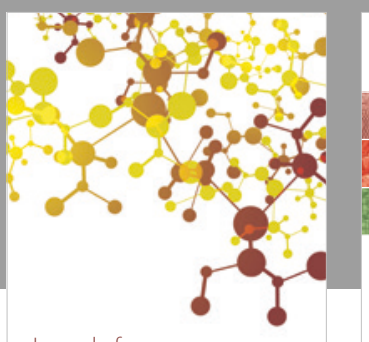

Journal of

Applied Chemistry
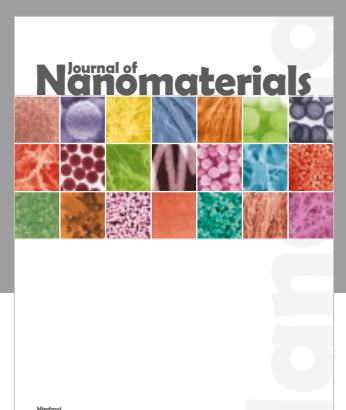

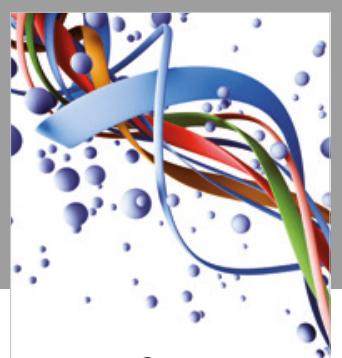

Scientifica

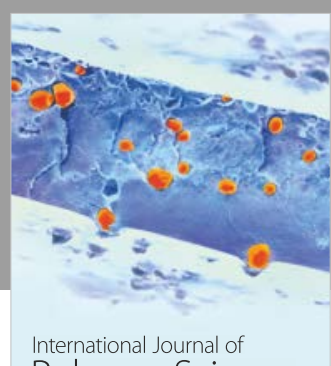

Polymer Science

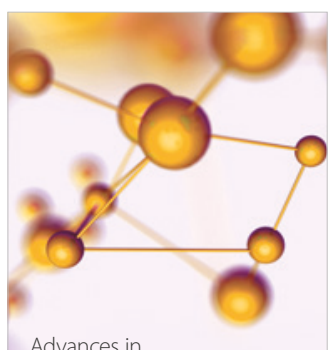

Physical Chemistry
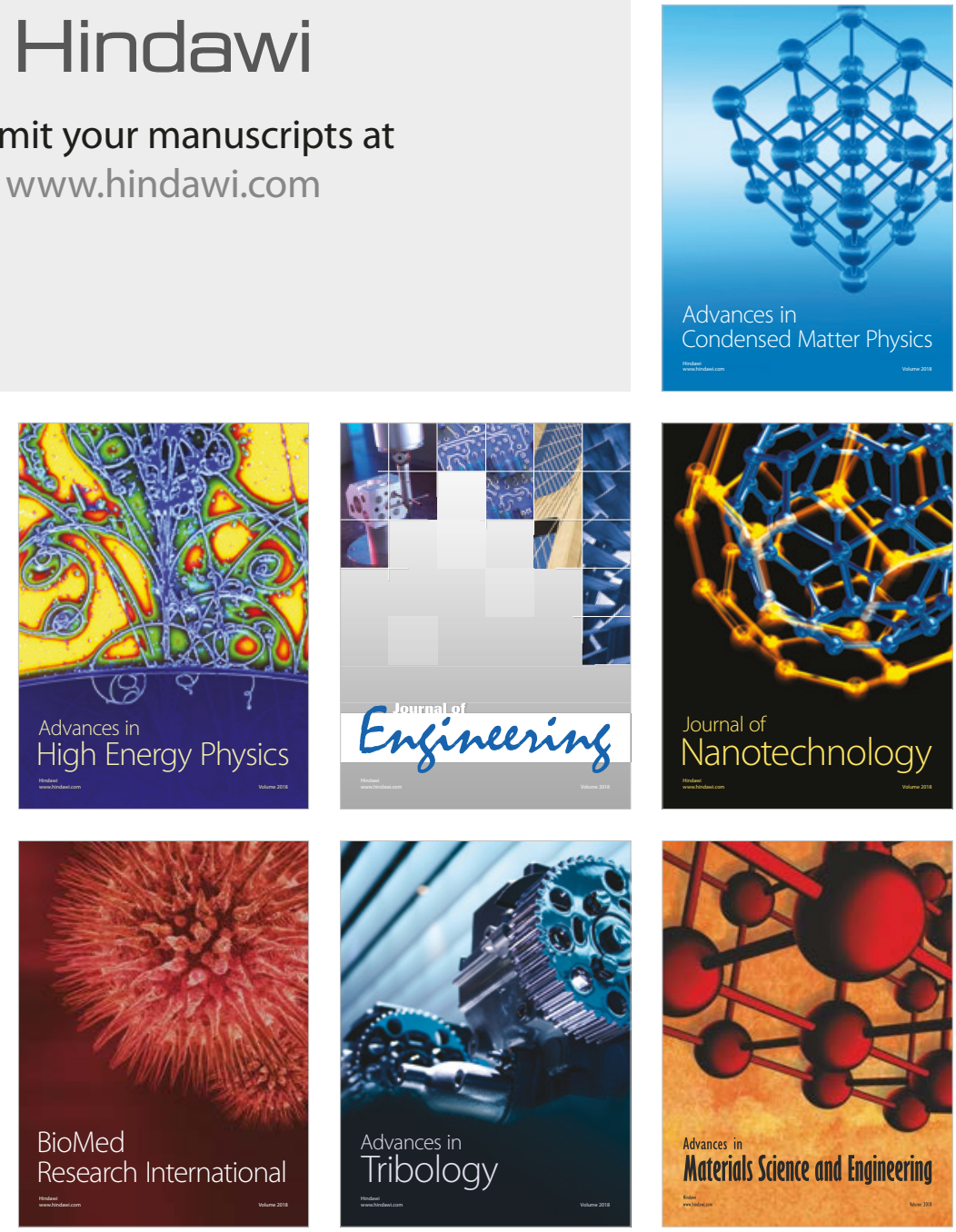